\title{
High- and low-temperature pyrolysis profiles describe volatile organic compound emissions from western US wildfire fuels
}

\author{
Kanako Sekimoto ${ }^{1,2,3,}$, Abigail R. Koss ${ }^{1,2,4, a,{ }^{*}}$, Jessica B. Gilman ${ }^{1}$, Vanessa Selimovic ${ }^{5}$, Matthew M. Coggon ${ }^{1,2}$, \\ Kyle J. Zarzana ${ }^{1,2}$, Bin Yuan ${ }^{1,2,6}$, Brian M. Lerner ${ }^{1,2, b}$, Steven S. Brown ${ }^{1,4}$, Carsten Warneke ${ }^{1,2}$, Robert J. Yokelson ${ }^{5}$, \\ James M. Roberts ${ }^{1}$, and Joost de Gouw ${ }^{1,2,4}$ \\ ${ }^{1}$ NOAA Earth System Research Laboratory (ESRL), Chemical Sciences Division, Boulder, CO 80305, USA \\ ${ }^{2}$ Cooperative Institute for Research in Environmental Sciences, University of Colorado Boulder, Boulder, CO 80309, USA \\ ${ }^{3}$ Graduate School of Nanobioscience, Yokohama City University, Yokohama, Kanagawa 236-0027, Japan \\ ${ }^{4}$ Department of Chemistry and Biochemistry, University of Colorado Boulder, Boulder, CO 80302, USA \\ ${ }^{5}$ Department of Chemistry, University of Montana, Missoula, MT 59812, USA \\ ${ }^{6}$ Institute for Environment and Climate Research, Jinan University, Guangzhou, China \\ ${ }^{a}$ now at: Department of Civil \& Environmental Engineering, Massachusetts Institute of Technology, \\ Cambridge, MA 02142, USA \\ ${ }^{b}$ now at: Aerodyne Research, Inc., Billerica, MA 01821, USA \\ *These authors contributed equally to this work.
}

Correspondence: Kanako Sekimoto (sekimoto@yokohama-cu.ac.jp)

Received: 19 January 2018 - Discussion started: 19 February 2018

Revised: 28 May 2018 - Accepted: 18 June 2018 - Published: 3 July 2018

\begin{abstract}
Biomass burning is a large source of volatile organic compounds (VOCs) and many other trace species to the atmosphere, which can act as precursors to secondary pollutants such as ozone and fine particles. Measurements performed with a proton-transfer-reaction time-of-flight mass spectrometer during the FIREX 2016 laboratory intensive were analyzed with positive matrix factorization (PMF), in order to understand the instantaneous variability in VOC emissions from biomass burning, and to simplify the description of these types of emissions. Despite the complexity and variability of emissions, we found that a solution including just two emission profiles, which are mass spectral representations of the relative abundances of emitted VOCs, explained on average $85 \%$ of the VOC emissions across various fuels representative of the western US (including various coniferous and chaparral fuels). In addition, the profiles were remarkably similar across almost all of the fuel types tested. For example, the correlation coefficient $r^{2}$ of each profile between ponderosa pine (coniferous tree) and manzanita (chaparral) is higher than 0.84 . The compositional differences between the two VOC profiles appear to be related to differences in pyrolysis processes of fuel biopoly-
\end{abstract}

mers at high and low temperatures. These pyrolysis processes are thought to be the main source of VOC emissions. "High-temperature" and "low-temperature" pyrolysis processes do not correspond exactly to the commonly used "flaming" and "smoldering" categories as described by modified combustion efficiency (MCE). The average atmospheric properties (e.g., OH reactivity, volatility, etc) of the high- and low-temperature profiles are significantly different. We also found that the two VOC profiles can describe previously reported VOC data for laboratory and field burns.

\section{Introduction}

Biomass burning is a large source of volatile organic compounds (VOCs) and other trace species to the atmosphere. Reactions involving these VOCs produce ozone and fine particles, which are important air pollutants and radiative forcing agents (Alvarado et al., 2009, 2015; Yokelson et al., 2009; Jaffe et al., 2012). Some VOCs from fires also have direct health effects (Naeher et al., 2007; Roberts et al., 2011). Biomass burning occurs in wildfires, controlled burns 
of wildland and agricultural fuels, and in residential wood stoves and industrial processes. Given the variety of fuels and burning conditions, it is unsurprising that the VOC composition of biomass burning emissions varies greatly between different fire states, locations, and studies. Therefore, it is important to understand VOC emissions from biomass burning in detail and develop a predictive capability that explains some of the variability in VOC emissions.

Multiple complex processes take place in biomass burning, including (i) distillation with release of water vapor and terpenes, (ii) pyrolysis of solid biomass giving off flammable gases, (iii) flaming combustion, and (iv) nonflaming processes loosely lumped with smoldering combustion such as glowing (gasification) of biomass (Yokelson et al., 1996, 1997; Collard and Blin, 2014; Liu et al., 2016). The main source of VOC emissions is pyrolysis of the polymers that form biomass such as cellulose, hemicellulose, and lignin. The temperature of the reaction and the physical characteristics of the biopolymer control which pyrolysis mechanism (e.g., depolymerization, fragmentation, or aromatization) is the main source of emitted VOCs (Yokelson et al., 1996, 1997; Collard and Blin, 2014; Liu et al., 2016). In a given fire, the processes (i)-(iv) occur simultaneously, but the relative importance of each process and temperature can change with time, which relates to the variability in integrated VOC emissions between different fires. This variability is often parameterized as a function of modified combustion efficiency $\left(\mathrm{MCE}=\Delta \mathrm{CO}_{2} /\left(\Delta \mathrm{CO}+\Delta \mathrm{CO}_{2}\right)\right)$ (Yokelson et al., 1996). $\mathrm{CO}_{2}$ and $\mathrm{CO}$ are representative gases emitted from the flaming and smoldering combustion processes, respectively, and are measured in most biomass burning studies. MCE is generally higher in flaming combustion $(>0.9)$ and lower in smoldering combustion (<0.9) (Akagi et al., 2011).

The National Oceanic and Atmospheric Administration (NOAA) led the Fire Influence on Regional and Global Environments Experiment (FIREX) 2016 laboratory intensive conducted at the US Forest Service Fire Sciences Laboratory in Missoula, Montana, to study emissions of trace gases and aerosol from wildfires. Emissions from various fuels representative of the western US were sampled under controlled conditions by extensive instrumentation (https://www.esrl. noaa.gov/csd/projects/firex/firelab/instruments.html, last access: 19 January 2018). Experiments included so-called stack burns, in which emissions from an evolving burn were entrained into a large-diameter stack and sampled by various instruments. VOCs were measured by several instruments, including a PTR-ToF-MS (proton-transfer-reaction time-of-flight mass spectrometer) which captured gas-phase emissions with a fast time response during stack burns. The measurements show variability in VOC composition as the fire shifts between a dynamic mix of distillation, pyrolysis, flaming combustion, and "smoldering" combustion (here we use smoldering as a rough term to include various "nonflame" processes such as gasification). Ions measured with the PTR-ToF-MS were interpreted using a combination of gas-chromatographic preseparation experiments, literature review, time-series analysis, and comparison to other instruments (Koss et al., 2018). Approximately $90 \%$ of the instrument signal could be attributed to identified VOCs.

The aims of this work are to understand the variation in gas-phase emissions both over the course of a fire and on a fire-integrated basis. Ultimately, this improved understanding of emissions variability could be used to simplify predictions of the emission of secondary organic aerosol (SOA) and ozone precursors. To do this, the VOCs observed by PTRToF-MS in stack burns were analyzed using positive matrix factorization (PMF). We show that much of the observed variability in VOCs can be explained by only two factors, and that these two factors are qualitatively related to the temperature of the pyrolysis processes, which are the main sources of the VOC emissions from biomass burning. Based on this result, the two factors are named as a high-temperature pyrolysis factor and a low-temperature pyrolysis factor. The two factors are compared between fuels. Importantly, the hightemperature factor is quantitatively similar between different fuels, and the same is true for the low-temperature factor. The VOCs present in each factor are discussed in terms of composition, reactivity with $\mathrm{OH}$, and propensity to form secondary organic aerosol. The relative importance of high- and low-temperature pyrolysis factors is quantified for each fuel and discussed with respect to physical properties of the fuel and the burn dynamics. We also investigate how well VOC emissions in biomass burning can be modeled by the two PMF emission profiles through comparisons with previously reported data from laboratory burns and wildfires. Finally, emissions of some specific compounds are discussed.

\section{Methods}

\subsection{VOC measurements by PTR-ToF-MS}

Fire emissions were measured during the FIREX 2016 intensive at the Fire Sciences Laboratory in Missoula, Montana. The facility consists of a large combustion chamber and has been described in detail previously (Christian et al., 2003, 2004; Burling et al., 2010).

VOC measurements were performed using several instruments, including a PTR-ToF-MS. This instrument employed a high-resolution ToF mass analyzer (Aerodyne Research Inc, MA, USA; Tofwerk AG, Thun, Switzerland) and measured with a time resolution of $2 \mathrm{~Hz}$. VOCs and some inorganic compounds were ionized by proton transfer from $\mathrm{H}_{3} \mathrm{O}^{+}$reagent ions. We include the inorganic compounds in the discussion of VOCs. Species with a proton affinity higher than that of water can be measured, which includes many unsaturated and polar compounds. The mass resolution of the instrument (3000-5000 FWHM $m / \Delta m$ ) was sufficient to determine the elemental composition of ions and separate many isobaric compounds. Before each fire, background air in the 
combustion chamber was measured directly for several minutes. The instrument has been described in detail by Yuan et al. (2016, 2017), and operation, calibration, and peak identification during the FIREX 2016 laboratory intensive were described by Koss et al. (2018).

\subsection{Fuel and biomass burn descriptions}

A total of 15 types of natural fuel mixtures, most of which are representative of important western US ecosystems, were burned (Table 1). The names below are largely taken from the dominant plant species: (i) ponderosa pine, (ii) lodgepole pine, (iii) loblolly pine, (iv) Douglas fir, (v) Engelmann spruce, (vi) subalpine fir, (vii) juniper, (viii) bear grass, (ix) ceanothus, (x) chamise-contaminated, (xi) chamise-uncontaminated, (xii) manzanita-contaminated, (xiii) manzanita-uncontaminated, (xiv) sagebrush, and (xv) excelsior (aspen wood shavings). "Contaminated" chaparral fuels (manzanita and chamise) were collected from a heavily air-polluted site near San Dimas, CA, while "uncontaminated" fuels were collected from a cleaner site in North Mountain, CA. Individual components of various fuel complexes, including canopy, litter, duff, and rotten wood, were also burned separately. Fuel moisture content ranged from 0.6 to $55.6 \%$, and instantaneous MCE ranged from 0.75 to 1 . Additional details on the fires and fuels are given by Selimovic et al. (2018), including pre- and postfire weight, weight of fuel components, and elemental composition $(\mathrm{C}$, $\mathrm{H}, \mathrm{N}, \mathrm{S}$, and $\mathrm{Cl}$ by weight). Each fuel type was burned several times. All fires consumed most of the fuel. The present experiments did not have a direct measurement of temperature within the fire, which is not homogeneous and therefore difficult to define. Rather, the air temperature of the emissions was measured by the FTIR instrument, located at the sampling inlet of the PTR-ToF-MS. The hot gases from the fire were mixed with air from the room, cooling the air significantly, but the trends in temperature are related to the initial temperature of the emitted gases.

\subsection{PMF analysis}

Data from 51 burns measured by PTR-ToF-MS (Table 1) were analyzed using positive matrix factorization, a numerical method that can be used to determine major compositional categories of emissions, their compositional profiles, and their relative enhancements over time. PMF was conducted using the PMF Evaluation Tool v. 2.08A (Ulbrich et al., 2009). The basic principles of PMF and application to atmospheric chemistry measurements have been previously described (Ulbrich et al., 2009; Paatero and Tapper, 1994; Paatero, 1997).

More than 1000 ions were quantified in the PTR-ToF-MS mass spectra between $m / z, 12-217$. Of these, 574 were selected for PMF analysis (Table S1 in the Supplement). These 574 ions were resolved from neighboring peaks, were en- hanced during at least one fire, and exclude primary (e.g., $\mathrm{H}_{3} \mathrm{O}^{+}$and $\mathrm{H}_{3} \mathrm{O}^{+}\left(\mathrm{H}_{2} \mathrm{O}\right)$ ) and contaminant ions (e.g., Teflon fragments and transition metals) (Koss et al., 2018). The ion signals (in units of normalized counts per second; ncps), which are normalized to the $\mathrm{H}_{3} \mathrm{O}^{+}$ion intensities and corrected for ToF-duty cycle, humidity dependence, and $\mathrm{H}_{3} \mathrm{O}^{+}$ ion depletion as described by Koss et al. (2018), were analyzed using PMF. Typically, raw ion signals in units of counts per second (cps) have been used for PMF analysis. However, cps VOC ion signals are affected by temporal variability (depletion and instability) in primary ion intensity and humidity during the fire. To obtain PMF results that exclude instrument effects, the normalized and corrected ion signals are used in this analysis. The uncertainties of the normalized and corrected ion signals were calculated based on those originating from the raw (cps) ion signals. We chose to use instrument signal rather than mixing ratio because many ion masses cannot be unambiguously related to a single VOC contributor: they have several contributors, or result from fragmentation, and cannot be converted to mixing ratio. For example, $\mathrm{C}_{7} \mathrm{H}_{13}^{+}(\mathrm{m} / z$ 97.101) is a fragmentary product ion of at least five different VOCs, whose relative contributions are different between fires. However, variability in these ion signals still contains information useful for PMF. To interpret the PMF results, we did convert to mixing ratio where possible (Sect. 2.4). A total of 528 compounds were quantified, of which 156 are identified VOCs. The PTR-ToF-MS measures $50-80 \%$ of total emitted nonmethane VOC mass, with uncertainty in this value due to semivolatile compounds (Hatch et al., 2017).

In this work, we applied PMF to extended time series, in which all fires of a particular fuel type (e.g., ponderosa pine) were consolidated into a single data matrix (Fig. S1 in the Supplement), as well as time series of single fire data. Each fuel type was burned several times. Some individual fires of a particular fuel did not necessarily capture the full possible range of high- and low-temperature fire conditions, because of variability in the relative amounts of fuel parts, fuel moisture content, when fuel was added, or other differences. PMF using the consolidated time series makes it possible to capture the widest possible range of fire conditions. This approach also simplifies the comparison of average emission profiles between different types of fuels. Details on preparation of ion signal and uncertainty datasets are described in the Supplement (Sect. S1).

The discussion in Sect. 3 is based on the two-factor PMF solutions. Out of the 574 ions, 434 ions were fitted well and together represented $99 \%$ of the total ion signal. A total of 140 ions were not well fitted, as the difference between their measurements and the PMF reconstruction was higher than $50 \%$; these ions are excluded from the factors presented here. Ulbrich et al. (2009) suggest that poor retrieval of ions with less than $5 \%$ of total signal is not uncommon. 


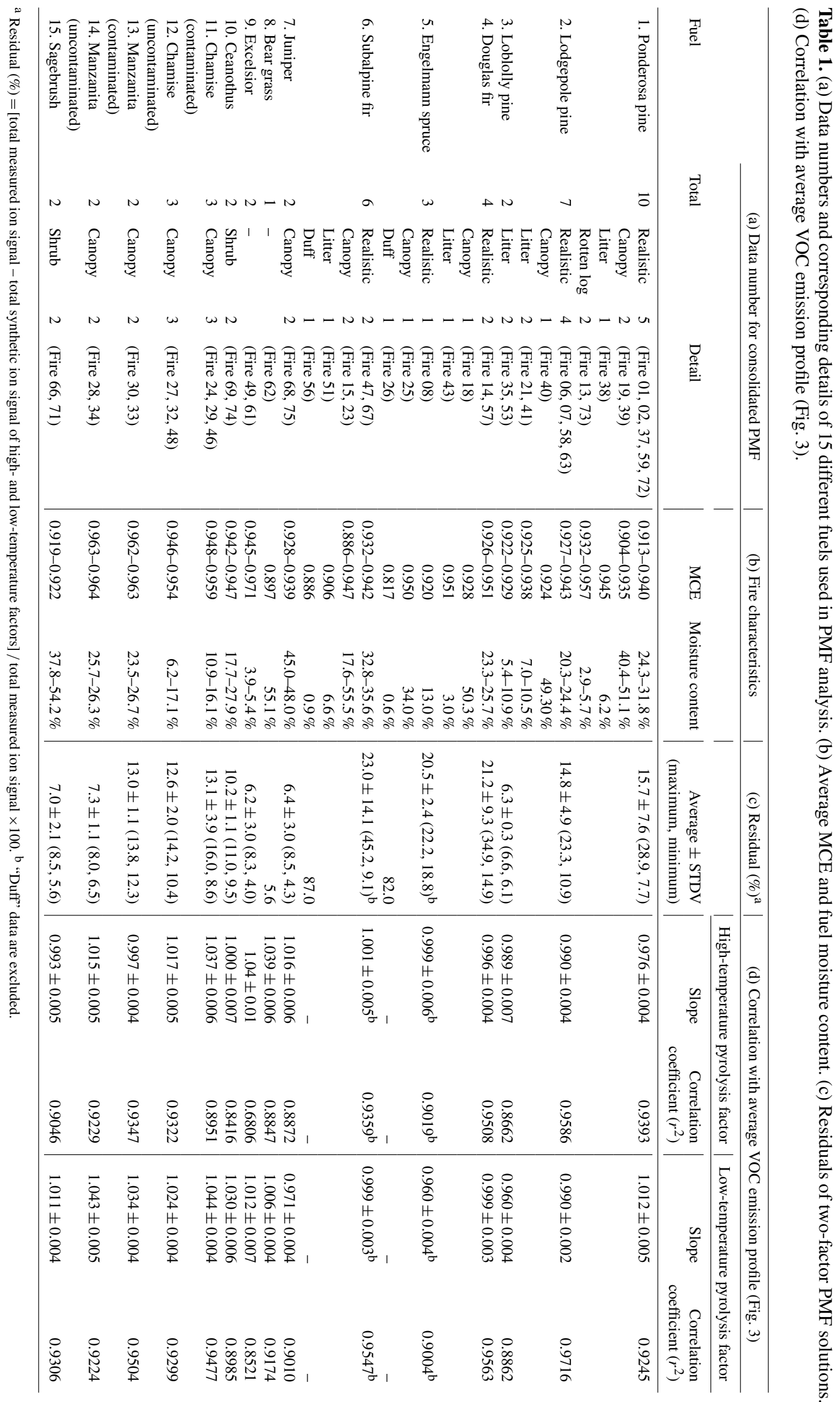




\subsection{Calculations of $\mathrm{OH}$ reactivity and volatility}

To characterize key chemical properties of the emission profiles derived from $\mathrm{PMF}$ analysis, we compare the $\mathrm{OH}$ reactivity and volatility of VOCs in each profile. These calculations require conversion of the emission profiles from instrument signal (ncps) to mixing ratio (ppbv). Fragment ions, cluster ions, and ions not well fitted by PMF were excluded from the 574 ions used in PMF analysis, and calibration factors were applied to the remaining 400 ions to convert them to mixing ratio. Of these, 156 have known VOC contributors, and account for $90 \%$ of the total instrument signal of nonprimary and noncontaminant ions between $m / z, 12-217$. (This corresponds to an average of $92 \%$ of the total VOC concentration detected by PTR-ToF-MS). Details on identification of the VOC contributors to ion masses and calibration are described by Koss et al. (2018).

We quantified the importance of the 156 identified ions to $\mathrm{OH}$ chemistry by multiplying the $\mathrm{VOC}+\mathrm{OH}$ reaction rate coefficient $\left(\mathrm{cm}^{3}\right.$ molecule $\left.{ }^{-1} \mathrm{~s}^{-1}\right)$ with the VOC fraction in the profile (ppbv VOC $\mathrm{ppbv}^{-1}$ of total VOC emitted) with a scaling factor to convert from VOC molar emission (ppbv VOC) to number density (molecule $\mathrm{cm}^{-3}$ at experimental conditions of $900 \mathrm{mbar}$ and $26^{\circ} \mathrm{C}$ ). The resulting $\mathrm{OH}$ reactivity is in units of per second per ppbv of total VOCs measured with PTR-ToF-MS (1 s ppbv ${ }^{-1}$ of total VOC emitted). For ions with more than one contributor, a weighted average rate constant was determined. Rate constants were taken from the literature (Atkinson and Arey, 2003; Manion et al., 2017; Cicerone and Zellner, 1983; Gilman et al., 2015) or estimated from structurally similar VOCs. Details can be found elsewhere (Koss et al., 2018).

We also quantified volatility using the saturation concentration at $25^{\circ} \mathrm{C}\left(\mathrm{C}_{0}, \mu \mathrm{g} \mathrm{m}^{-3}\right)$. Saturation concentrations were taken from the literature (Rumble, 2017-2018; NIST Chemistry WebBook, 2017; Yaws, 2015) where possible, and otherwise estimated based on the elemental composition of the ion ( $\mathrm{Li}$ et al., 2016). Volatility determined from elemental composition is uncertain, especially for compounds with very low volatility where the uncertainty can be several orders of magnitude ( $\mathrm{Li}$ et al., 2016). We determined volatility for the 400 nonfragmentary ions. We define volatility bins as follows, after $\mathrm{Li}$ et al. (2016): volatile organic compounds $\left(\mathrm{C}_{0}>3 \times 10^{6} \mu \mathrm{g} \mathrm{m}^{-3}\right)$, intermediate volatility compounds (IVOCs, $300<\mathrm{C}_{0}<3 \times 10^{6} \mu \mathrm{g} \mathrm{m}^{-3}$ ), and semivolatile compounds (SVOCs, $0.3<\mathrm{C}_{0}<300 \mu \mathrm{g} \mathrm{m}^{-3}$ ). Separation into such volatility bins is commonly used as an aid to discussion of SOA formation potential and gas-particle partitioning (Donahue et al., 2011).

\section{Results and discussion}

\subsection{Two-factor parameterization of VOC emissions from biomass burning}

Figure 1a shows the time series of selected VOC ion signals from burning a representative mixture of ponderosa pine fuels. In these lab fires, total VOC emissions (red line in Fig. 1a) often increase immediately and substantially during the initial combustion (for $170 \mathrm{~s}$ after starting the burn in this example), and then total emissions gradually decrease as the flames die out. Emissions of individual VOCs can be seen to fall into two categories: (i) higher emissions during the first part of the fire, e.g., naphthalene, which correlates with the PMF factor we will largely attribute below to hightemperature pyrolysis (blue line in Fig. 1a), and (ii) higher emissions during the latter part of the fire, e.g., syringol, which correlates with the PMF factor we will attribute below to low-temperature pyrolysis (green line in Fig. 1a). This separation into two categories is typical for most fires, with a few exceptions discussed later (e.g., burns of duff and rotten wood).

These two PMF factors (Fig. 1b) describe the total VOC emissions remarkably well for most fuels: residuals (the differences between the measured ion signals and the calculated ion signals based on the PMF fits) are less than $15 \%$ on average, except for Douglas fir, Engelmann spruce, and subalpine fir for which the residual average is $20-25 \%$. The residuals for individual fuels are summarized in Table 1c. For most of the fuels, the time series of the first and second factors are strongly correlated with those of naphthalene and syringol, respectively (correlation coefficient $\left.\left(r^{2}\right)>0.74\right)$ ). On the contrary, emissions of compounds mainly from flaming or nonpyrolysis smoldering processes, such as $\mathrm{CO}, \mathrm{CO}_{2}$, and $\mathrm{NO}_{x}$ (Fig. 1c), do not correlate well with the individual PMF factors (more detailed discussion is given in Sect. 3.5). This indicates that the two PMF factors do not correspond to the flaming and smoldering combustion processes that are described by MCE and often referenced in biomass burning literature. The main source of VOC emissions is pyrolysis of fuel biopolymers, and not the flaming and/or other combustion processes. Therefore, we primarily attribute these two factors to high-temperature pyrolysis and low-temperature pyrolysis, respectively, and will use these names to describe these factors in this work. Our association between the factors and pyrolysis temperature is related more rigorously to the distribution of products observed as a function of pyrolysis temperature in the next section. When allowing more than two factors in PMF, the time series and mass spectral profiles of the additional factors can be represented as an "intermediate" or "splitting" of high- and/or low-temperature factors which can be described by a linear combination of the two factors. As examples, Figs. S2 and S3 show the correlation between $n$-factor solutions $(n=3,4)$ and PMF results from high- and low-temperature factors for ponderosa pine 


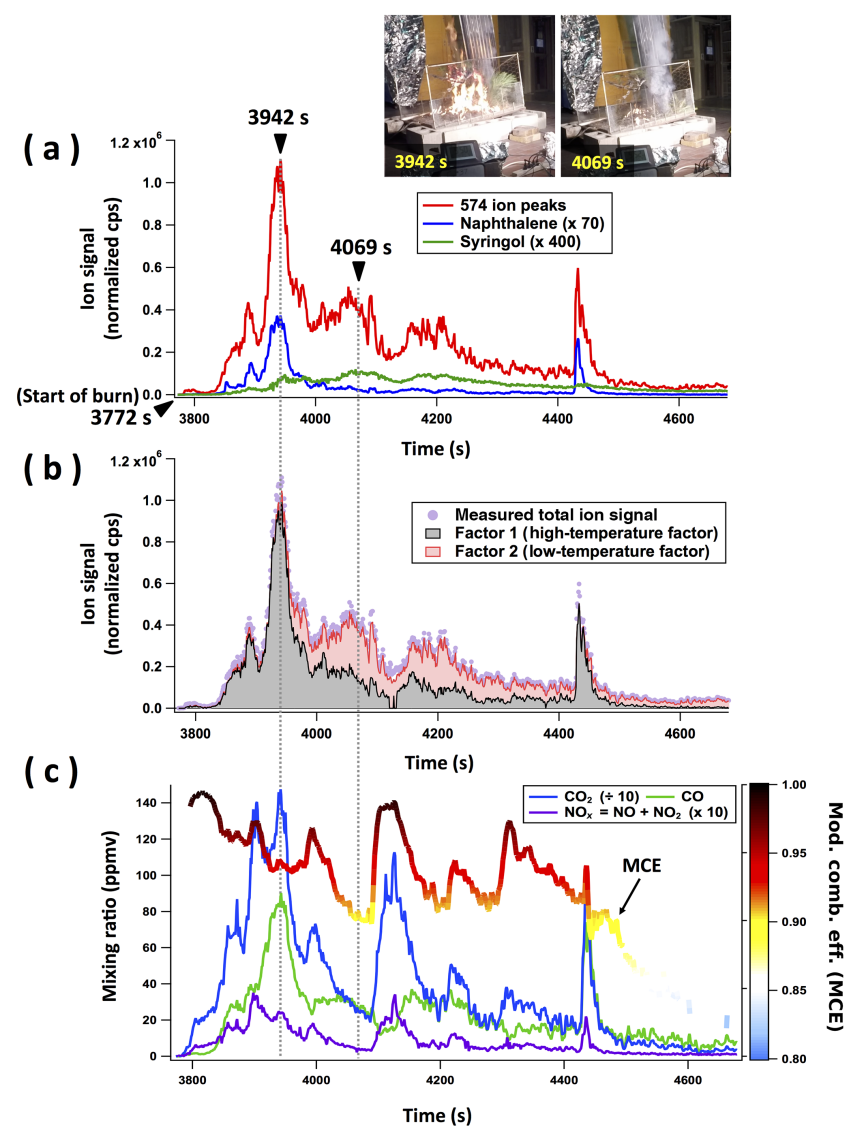

Figure 1. Results for an example burn of ponderosa pine realistic mixture (Fire no. 37). (a) Time series of ion signals of 574 ion peaks, naphthalene $\left(\mathrm{C}_{10} \mathrm{H}_{8} \cdot \mathrm{H}^{+}, m / z, 129.070\right)$, and syringol $\left(\mathrm{C}_{8} \mathrm{H}_{10} \mathrm{O}_{3} \cdot \mathrm{H}^{+}, m / z\right.$ 155.070). (b) PMF results of two-factor solution. The grey and pink colors are stacked, not overlapped. (c) Time series of mixing ratios of $\mathrm{CO}_{2}, \mathrm{CO}$, and $\mathrm{NO}_{x}$ measured by openpath Fourier transform infrared (OP-FTIR) optical spectroscopy and the modified combustion efficiency (MCE) (Selimovic et al., 2018). The MCE trace is colored by the key and scale on the right.

datasets. This suggests that only two factors, i.e., high- and low-temperature pyrolysis factors, were needed to explain most of the variability we observed for the VOC emissions from biomass burning.

There are notable exceptions to the two-factor solution, including an infrequently observed, but important, third factor that we call a "distillation" factor, and a fourth profile observed during burns of duff. Several fires contain a distillation phase, in which a brief burst of VOCs, typically enriched in terpenes, is emitted immediately prior to ignition. However, PMF captured this phase for only a limited number of burns in which the distillation phase contained sufficient gas-phase emissions and lasted long enough $(\sim 30 \mathrm{~s})$. When a two-factor solution is used, the terpenes are largely grouped with the high-temperature pyrolysis factor. Duff is defined as a "layer of moderately to highly decomposed leaves, needles, fine twigs, and other organic material found between the mineral soil surface and litter layer of forest soil" (Reardon, 2007). The duff PMF solutions have residuals larger than $80 \%$ when solved with only two factors. This means that duff burns have a unique VOC emission pattern that cannot be explained by only high- and low-temperature factors. These exceptions are discussed in more detail later.

\subsection{VOC emission profiles of high- and low-temperature pyrolysis factors}

The mass spectral profiles of the relative abundances of emitted VOCs for the individual PMF factors obtained from a given fuel type are similar for replicate burns of the same fuel type. When comparing the PMF profiles for two individual burns of the ponderosa pine realistic mixture, the correlation coefficient $\left(r^{2}\right)$ is higher than 0.92 for both the high- and low-temperature pyrolysis factors (Fig. 2a). Importantly, the mass spectra for the high-temperature pyrolysis factor are also very similar between different fuels, and the same is true for the low-temperature pyrolysis factor. For example, the correlations of each profile between (i) Douglas fir and ponderosa pine, (ii) manzanita (chaparral) and ponderosa, and (iii) bear grass and ponderosa have a slope near 1 and $r^{2} \geq 0.83$ (Fig. 2b-d). In contrast, the correlation between the high- and low-temperature mass spectra is visually clearly lower $\left(r^{2}<0.69\right.$, Fig. 2e). Figure 3 shows the average VOC emission profiles of the two factors obtained using PMF results of 15 different fuels. The fractions of individual ion peaks in the emission profiles are summarized in Table S1. These average profiles are in good agreement with profiles of individual fuels: a best fit of $0.96<$ slope $<1.04$ and $r^{2}>0.84$, except for a high-temperature factor of excelsior with $r^{2}=0.68$ (Table 1d and Fig. S4). Excelsior is an unusual fuel in that it consists of fine shavings of a single fuel component (wood). VOC composition in high- and lowtemperature profiles is discussed in Sect. 3.3.1.

The compositional differences between the two profiles can be qualitatively explained by the temperature of the pyrolysis reactions thought to be the main production mechanism of the VOCs, such as depolymerization, fragmentation, and aromatization (Yokelson et al., 1996, 1997; Collard and Blin, 2014; Liu et al., 2016). This is illustrated by the relative contributions from the high-temperature versus low-temperature factors for most emitted VOCs. VOCs expected from high-temperature processes have a higher emissions contribution from the high-temperature factor, and likewise for low-temperature VOCs and the low-temperature factor.

Figure $4 \mathrm{a}$ shows the contribution of each factor to selected pyrolysis products from major fuel biopolymers, i.e., hemicellulose, cellulose, and lignin. The contributions of individual VOCs are expressed by their normalized fractions ( $F_{\text {high- } T}$ and $F_{\text {low- } T}$ ) of high- and low-temperature factors: $F_{\text {high- } T}=$ Fraction $_{\text {high- } T} /\left(\right.$ Fraction $_{\text {high }-T}+$ Fraction $\left._{\text {low }-T}\right)$ and $F_{\text {low }-T}=$ Fraction $_{\text {low }-T} /\left(\right.$ Fraction $_{\text {high- } T}+$ Fraction $\left._{\text {low }-T}\right)$, 
(a) Ponderosa (Fire 72) vs. ponderosa (Fire 02)

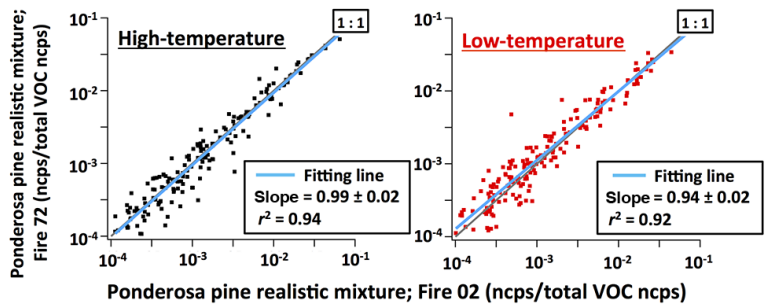

(c) Manzanita vs. ponderosa pine

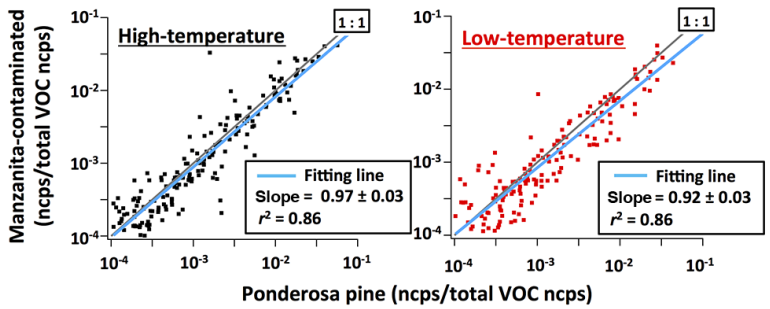

(b) Douglas fir vs. ponderosa pine

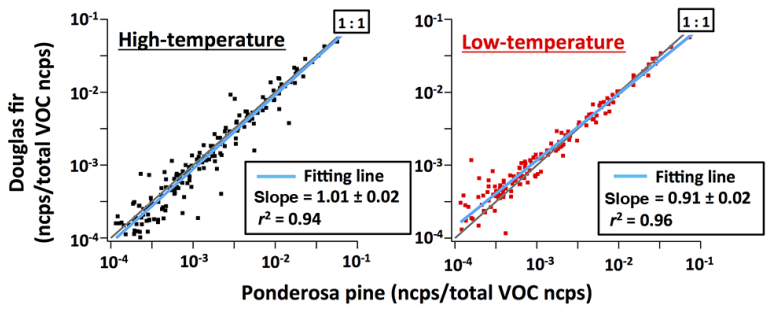

(d) Bear grass vs. ponderosa pine

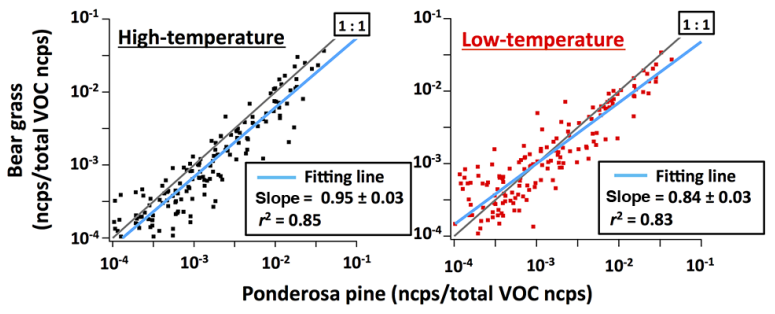

(e) Low-temperature vs. high-temperature pyrolysis factor

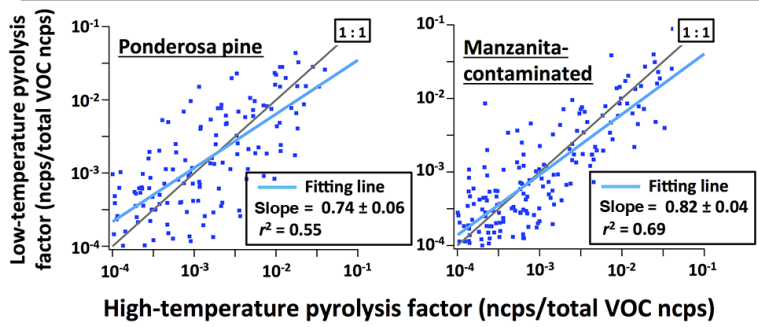

Figure 2. Comparison of mass spectral profiles: (a) ponderosa pine realistic mixture (Fire no. 72) vs. ponderosa pine realistic mixture (Fire no. 02) for high- and low-temperature pyrolysis factors. (In this case, PMF was separately performed for data of Fire no. 02 and no. 72.) (b) Douglas fir vs. ponderosa pine for high- and low-temperature factors. (c) Manzanita (contaminated) vs. ponderosa pine for both the factors. (d) Bear grass vs. ponderosa pine for both the factors. (e) Low- vs. high-temperature pyrolysis factor for ponderosa pine and manzanita (contaminated). Data points in individual panels correspond to well-fitted 434 ion peaks. Slope and correlation coefficient $\left(r^{2}\right)$ are obtained using logarithmic fraction, i.e., $\log ($ ncps per total VOC ncps).

where Fraction ${ }_{\text {high- } T}$ and Fraction ${ }_{\text {low- } T}$ correspond to fractions (in ncps per total VOC ncps) of individual species in the high- and low-temperature VOC profiles (Fig. 3), respectively. Figure $4 \mathrm{~b}$ also shows the relationship between pyrolysis temperature and representative products for individual biopolymers as reported in the literature (Collard and Blin, 2014). During the heating of biomass, different chemical bonds within the biopolymers are broken, which results in the release of VOCs and in rearrangement reactions within the matrix of the residue. Low-temperature pyrolysis breaks the bonds between the monomer units of the polymers. Depolymerization in lignin $\left(300-500^{\circ} \mathrm{C}\right)$ produces guaiacols, (iso)eugenol, and syringol. Furans and furfurals are dominantly formed from cellulose and hemicellulose $\left(300-400^{\circ} \mathrm{C}\right)$. Emissions of these compounds have a larger contribution from the low-temperature factor $\left(F_{\text {low- } T}=60-100 \%\right)$. Higher temperatures allow reaction of functional groups and covalent bonds in polymers and monomers. The resulting fragmentation emits various VOCs: for example, hydroxyacetone, acetaldehyde, and acetic acid from depolymerization of cellulose and/or hemicellulose. These VOCs have roughly equal contributions from lowand high-temperature factors. The release of oxygenated compounds during depolymerization and fragmentation increases the carbon percentage of the residual biopolymers. Benzene rings and aromatic polycyclic structures form, which is termed char. Higher temperature pyrolysis breaks progressively stronger bonds in char $\left(>500^{\circ} \mathrm{C}\right)$. This aromatization process gives off aromatic compounds with short substituents (e.g., phenol), nonsubstituted aromatics (e.g., benzene), and polycyclic aromatic hydrocarbons (PAHs, such as naphthalene). Most of those aromatics have a large contribution from the high-temperature factor $\left(F_{\text {high- } T}=60\right.$ $100 \%$ ). As the temperature increases, substituents of the aromatic rings disappear and PAHs are dominantly produced. This is consistent with the contribution of the high-temperature factor to phenol $\left(F_{\text {high- } T}=60 \%\right)$, benzene $(77 \%)$, and naphthalene (92\%). 


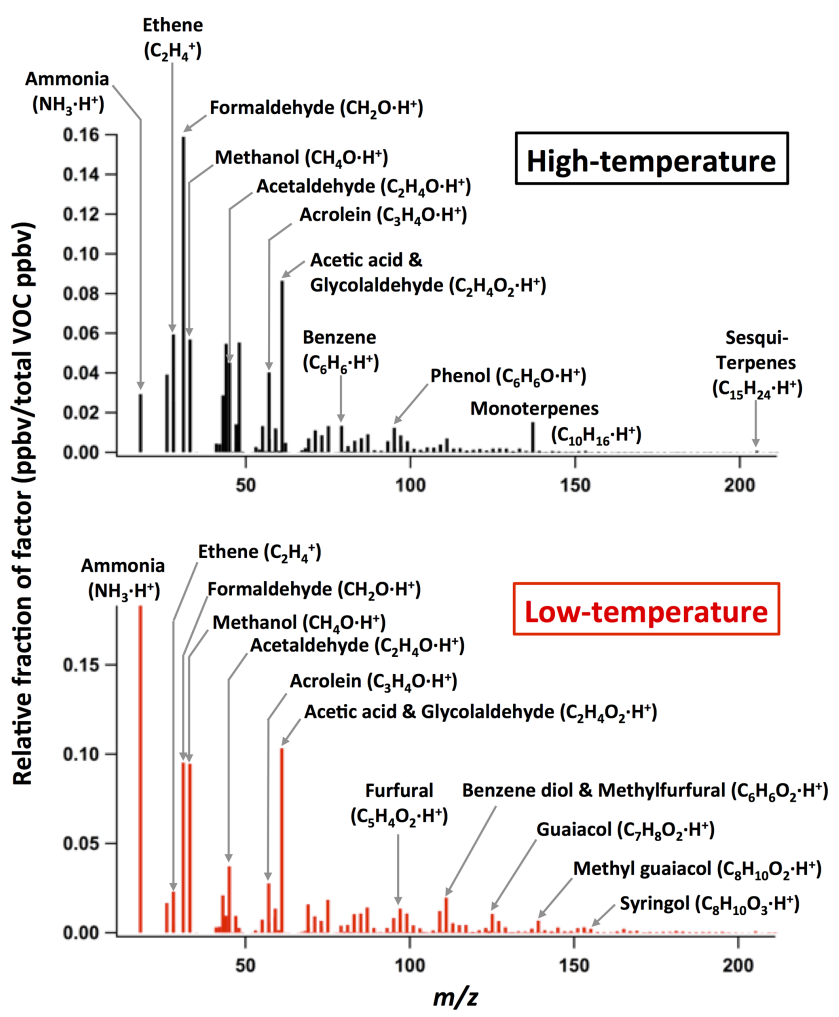

Figure 3. Average VOC emission profiles of high- and lowtemperature pyrolysis factors, obtained using consolidated PMF results of 15 different fuels.

These many diverse chemical processes are likely happening simultaneously during a fire, and their relative intensities may change based on fuel composition, fuel moisture content, or other as-yet poorly defined parameters. However, the net result of all these variables is the emission of just two major compositional groups. The VOCs that comprise these two groups mostly consist of the pyrolysis products described above and their analogs. During most of these fires, the emissions of any particular VOC can be described by a linear combination of the high-temperature and low-temperature pyrolysis time series. Some VOCs are emitted mainly from the high-temperature pyrolysis, some mainly from the lowtemperature profile, and others have a mixed contribution. This is quantified by $F_{\text {high- } T}$ as described above. We sorted the VOCs by $F_{\text {high- } T}$, to show how the chemical composition of emissions changes from high- to low-temperature pyrolysis process. Figure 5 shows the chemical characteristics of compounds that are mostly emitted in the high-temperature pyrolysis $\left(F_{\text {high- } T}=80-100 \%\right.$ in panel a), mostly emitted in the low-temperature pyrolysis $\left(F_{\text {high- } T}=0-20 \%\right.$ in panel e), or have mixed contributions from both types of pyrolysis $\left(F_{\text {high- } T}=60-80 \%\right.$ in panel b, 40-60\% in c, and 20-40\% in d). $F_{\text {high- } T}$ of each individual VOC is shown in Fig. S5. In the category emitted mostly by the high-temperature pyrolysis, important compounds include alkyl-substituted aromat- ics and aliphatic alkenes (Fig. 5a and b), whereas carbonyls have more equal contributions from the high- and lowtemperature pyrolysis processes. It should be noted that terpenes (e.g., (oxygenated) monoterpenes and isoprene) emitted from distillation are grouped with the high-temperature pyrolysis (Fig. 5a and b; Sect. 3.6).

Several nitrogen $(\mathrm{N})$-containing compounds also fall into high- or low-temperature categories, consistent with behavior previously reported in the literature. The main $\mathrm{N}$ containing compounds detected by PTR-ToF-MS are isocyanic acid (HNCO), nitrous acid (HONO), hydrogen cyanide $(\mathrm{HCN})$, and ammonia $\left(\mathrm{NH}_{3}\right)$. $\mathrm{HNCO}, \mathrm{HONO}$, and HCN have a high contribution of the high-temperature factor ( $F_{\text {high- } T}=80-100 \%$ in Fig. 5a), while $\mathrm{NH}_{3}$ falls into the category with a large contribution from the low-temperature factor $\left(F_{\text {low- } T}=86 \%\right.$ in Fig. 5e). Nitrogen in biomass typically exists as amino acids or proteins and pyrrole or pyridine (aromatic N-heterocycles). During the pyrolysis of those $\mathrm{N}$ functionalities at high temperature $\left(700-1100^{\circ} \mathrm{C}\right), \mathrm{HCN}$ is identified as the main product in most cases (Johnson and Kang, 1971; Haidar et al., 1981; Patterson et al., 1968; Houser et al., 1980). $\mathrm{NH}_{3}$, resulting from the lower-temperature pyrolysis of proteins, has been classified as smoldering combustion gases and falls here into the low-temperature profile (Yokelson et al., 1996).

The present analysis predominantly focuses on VOCs. The VOC emissions from biomass burning are dominated by pyrolysis reactions of biopolymers. However, not all species are emitted from pyrolysis reactions. For example, flaming combustion releases $\mathrm{CO}_{2}, \mathrm{NO}_{x}, \mathrm{HONO}$, black carbon, etc. This is a separate process and cannot be expected to be captured by our VOC framework. In Sect. 3.5 we show that MCE, which delineates flaming versus smoldering combustion, is a poorer descriptor of VOC variability than the high- versus low-temperature pyrolysis framework.

\subsection{Chemical characteristics of VOC emissions depending on pyrolysis temperature}

\subsubsection{VOC composition}

The VOC emission profiles for the high- and lowtemperature factors are shown in Fig. 3 and they mainly consist of hydrocarbons, oxygenates with $n=1-7$ oxygen atoms, and nitrogen- and/or sulfur-containing hydrocarbons (Fig. 6). In each emission profile, about half of the fraction (in ppbv) is accounted for by a combination of the following seven compounds: (i) ethene $\left(\mathrm{C}_{2} \mathrm{H}_{4}\right)$, (ii) formaldehyde (HCHO), (iii) methanol $\left(\mathrm{CH}_{3} \mathrm{OH}\right)$, (iv) acetaldehyde $\left(\mathrm{CH}_{3} \mathrm{CHO}\right)$, (v) acrolein $\left(\mathrm{CH}_{2}=\mathrm{CHCHO}\right)$, (vi) acetic acid $\left(\mathrm{CH}_{3} \mathrm{COOH}\right)$ and glycolaldehyde $\left(\mathrm{HOCH}_{2} \mathrm{CHO}\right)$, and (vii) ammonia $\left(\mathrm{NH}_{3}\right)$. The other half includes several fundamental structures, with a variety of functionalities, as discussed later. Oxygenates with one oxygen are predominant in both emission profiles, accounting for $39 \%$ of molar emis- 

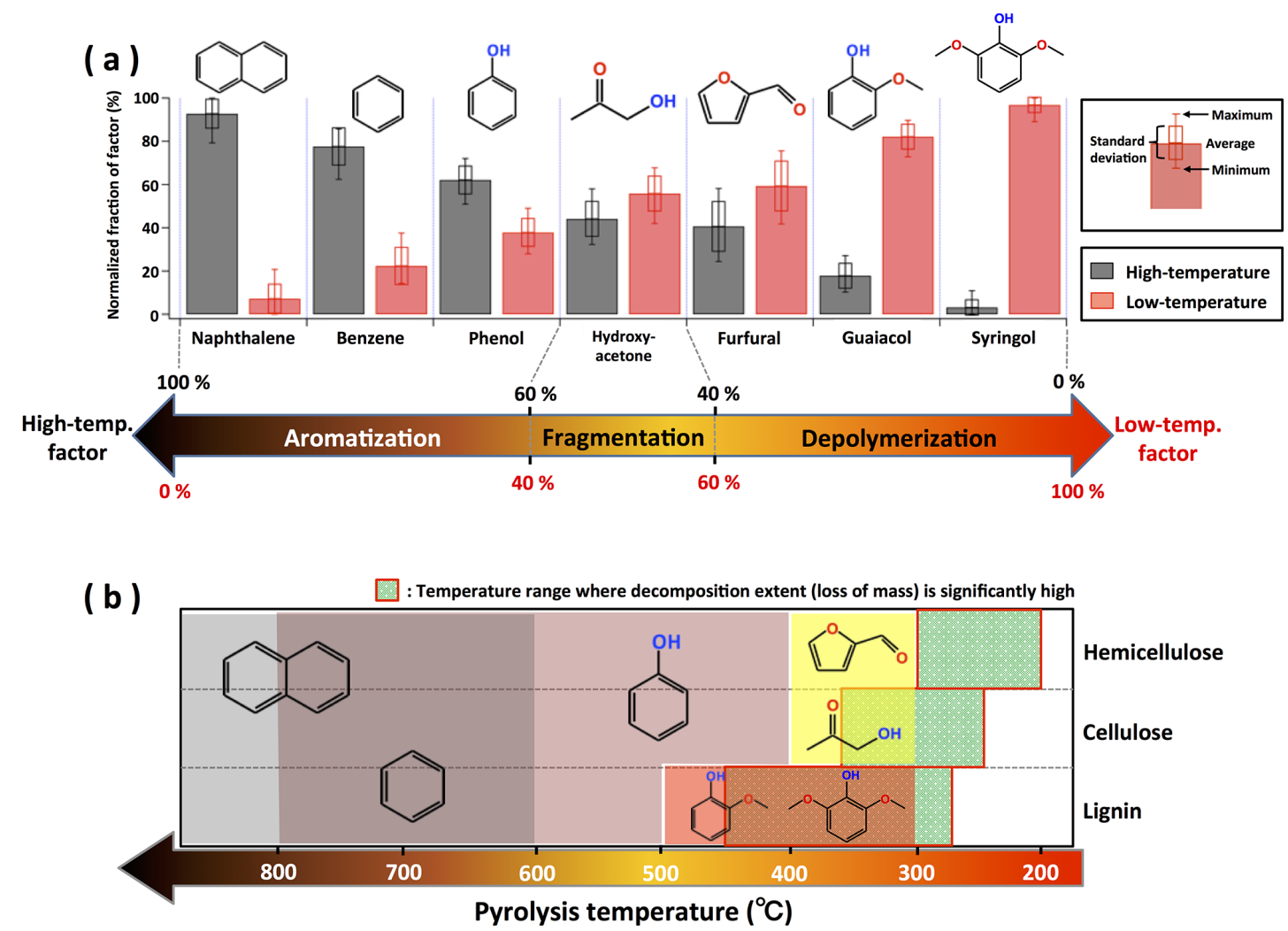

Figure 4. (a) Normalized fraction of factors for selected biomass pyrolysis products, obtained using PMF results of 15 different fuels. (b) Diagram of the relationship between pyrolysis temperature and products for hemicellulose, cellulose, and lignin, as reported in the literature (Collard and Blin, 2014). Individual color bars show the temperature range to form specific products described by chemical structures.

sions in the high-temperature profile and $36 \%$ in the lowtemperature profile. Emissions of highly oxygenated compounds ( $\geq 2$ oxygen atoms) and ammonia are higher in the low-temperature profile than in the high-temperature profile. The fractions of hydrocarbons and compounds that contain both $\mathrm{N}$ and $\mathrm{O}$, such as $\mathrm{HNCO}$, are lower in the lowtemperature profile.

VOCs emitted from biomass burning can be generally organized into major structural groups: furans, aromatics, oxygenated aromatics, aliphatic compounds, and so on. Within each structural category, compounds can have various functionalities, such as alcohol or alkene substituents (Hatch et al., 2015). VOC composition, classified by 11 structures and 17 functionalities, is shown in Figs. 7 and 8. Some VOCs have multiple functional groups. These are counted once in each relevant category. For example, guaiacol is counted in "Oxygenated aromatic" structural category as "Alcohol" and "Ether (methoxy)" functional groups.

The most dominant emissions are attributable to aliphatic oxygenates, i.e., $62 \%$ of molar emissions in the hightemperature profile and $60 \%$ in the low-temperature profile (Fig. 7). This is due to the specific compounds (ii)(vi) described above. The low-temperature profile is twice as rich in aromatic oxygenates ( $\geq 2$ oxygen atoms) and furans as the high-temperature profile, while the high-temperature profile is enriched in aliphatic (mostly alkenes) and aromatic hydrocarbons. Terpenes (including isoprene, monoterpenes, sesquiterpenes, and oxygenated monoterpenes) emitted from distillation, not from pyrolysis, are dominantly grouped with the high-temperature factor. Compared to the low-temperature profile, the high-temperature profile is enriched in the following functional groups: $\mathrm{C}-\mathrm{C}$ double bond $(>\mathrm{C}=\mathrm{C}<$ ), $\mathrm{C}-\mathrm{C}$ triple bond $(-\mathrm{C} \equiv \mathrm{C}-)$, diene $(>\mathrm{C}=\mathrm{C}$ $\mathrm{C}=\mathrm{C}<$ ), polycyclic aromatic hydrocarbon $(\mathrm{PAH})$, nitrile $(-\mathrm{C} \equiv \mathrm{N})$, amide $(-\mathrm{C}(=\mathrm{O})-\mathrm{N}-)$, nitro $\left(-\mathrm{NO}_{2}\right)$, nitrate $\left(-\mathrm{NO}_{3}\right)$, thiol/sulfide (-S-(H)) (Fig. 8). The low-temperature profile is enriched in alcohols $(-\mathrm{OH})$, ethers (mostly methoxy groups: $\left.\mathrm{O}-\mathrm{CH}_{3}\right)$, esters $(-\mathrm{C}(=\mathrm{O})-\mathrm{O}-)$, and amines $\left(-\mathrm{NH}_{2}\right.$; mostly ammonia). The emissions of compounds with carbonyl groups $(>\mathrm{C}=\mathrm{O})$ and acids $(-\mathrm{C}(=\mathrm{O})-\mathrm{OH}-)$ are similar. These results are consistent with the contributions of VOC to the high- and low-temperature factors described in Sect. 3.2.

\subsubsection{OH reactivity}

The hydroxyl radical $(\mathrm{OH})$ is an important driver of daytime oxidation chemistry. Quantifying the VOC reactivity with $\mathrm{OH}$ provides insight into which VOC emissions may 


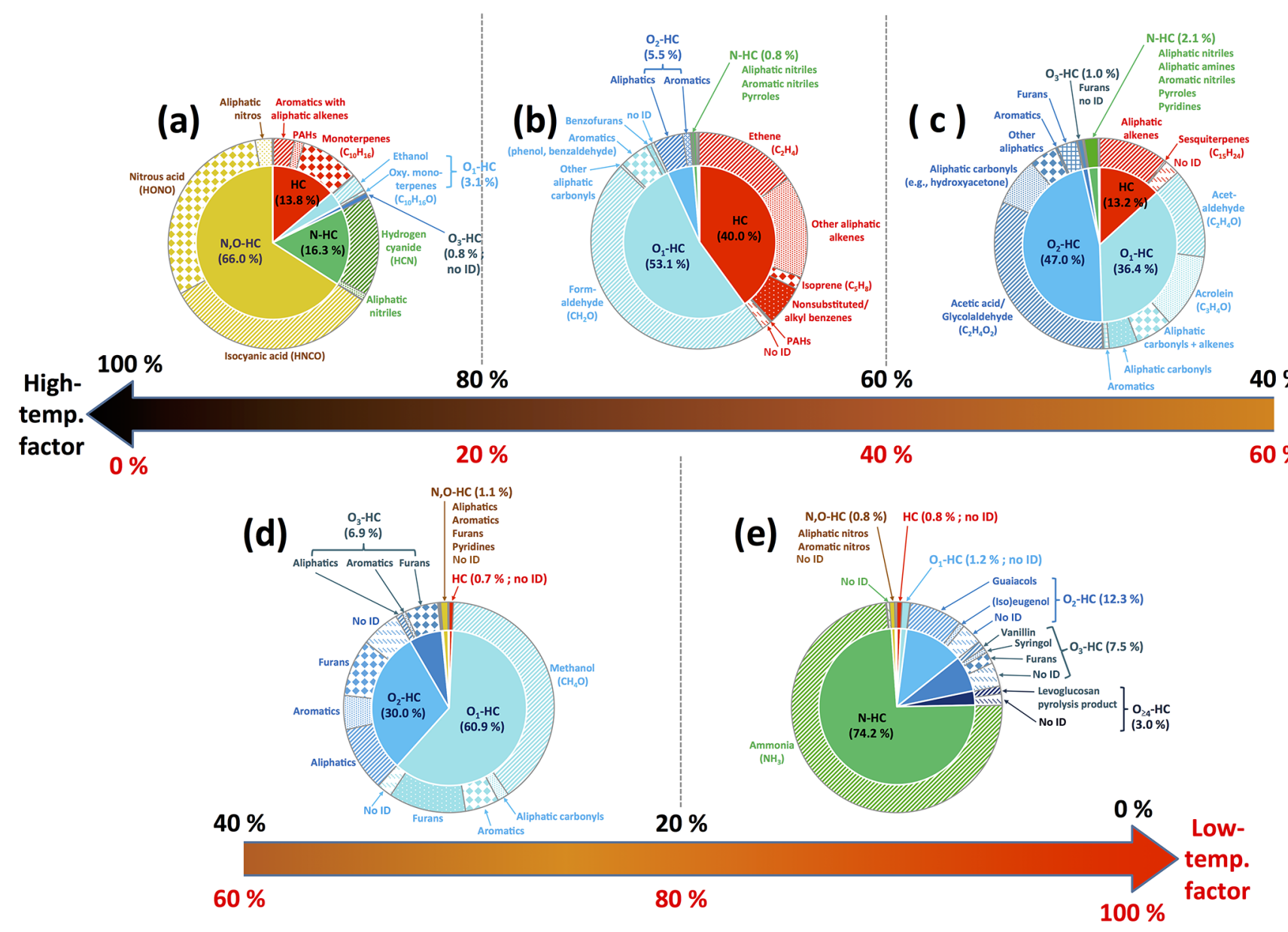

Hydrocarbons (HC) $\square \mathrm{N}$-containing hydrocarbons (N-HC) $\square \mathrm{N}$ and O-containing hydrocarbons (N,O-HC) O-containing hydrocarbons $\left(\mathrm{O}_{n}-\mathrm{HC}, n\right.$ : number of oxygen atom) $\square n=1 \square n=2 \square n=3 \square n \geq 4$

Figure 5. Contributions, shown as normalized fractions, of VOCs relative to the high- and low-temperature factors: (a) $F_{\mathrm{High}-T}=100-80$ and $F_{\text {Low- } T}=0-20 \%$, (b) $F_{\text {High- } T}=80-60$ and $F_{\text {Low- } T}=20-40 \%$, (c) $F_{\text {High- } T}=60-40$ and $F_{\text {Low }-T}=40-60 \%$, (d) $F_{\text {High- } T}=40-20$ and $F_{\text {Low- } T}=60-80 \%$, and (e) $F_{\text {High- } T}=20-0$ and $F_{\text {Low- } T}=80-100 \%$. In this figure, molar emissions (in units of ppbv) of all the ion peaks in VOC emission profiles (Fig. 2b) are described. The inner circle in each pie chart shows the elemental composition of the emissions. The outer circle provides more detailed information on specific compounds, structures, and functionalities found in each group. Details of molar fractions in each category are summarized in Table S2.

be most important for ozone and secondary organic aerosol formation. Interestingly, the two profiles have a similar average per-molecule (weighted by abundance) rate constant with $\mathrm{OH}: 15.7 \times 10^{-12} \mathrm{~cm}^{3}$ molecule ${ }^{-1} \mathrm{~s}^{-1}$ for the hightemperature profile and $15.8 \times 10^{-12} \mathrm{~cm}^{3}$ molecule ${ }^{-1} \mathrm{~s}^{-1}$ for the low-temperature profile. However, the reactivity is provided by very different VOCs in each profile. Aliphatic oxygenates are important in both profiles, but more so in the high-temperature profile (30\% of reactivity) than in the low-temperature profile ( $24 \%$ of reactivity). In the hightemperature profile, the reactivity also has a large contribution from terpenes and aliphatic hydrocarbons, while in the low-temperature profile, the reactivity is largely due to furans and aromatics (Fig. 9a). Since the total VOC emissions in real-world fires come from a mixture of the high- and lowtemperature pyrolysis factors, the total $\mathrm{OH}$ reactivity of fresh emissions should scale directly with VOC concentration.

\subsubsection{Volatility}

Volatility is another important chemical characteristic affecting secondary organic aerosol yield and formation rate. The low-temperature emission profile contains more compounds that are of higher molecular weight, more oxygenated, and of lower volatility (Fig. 9b). Oxygenated aromatics have 


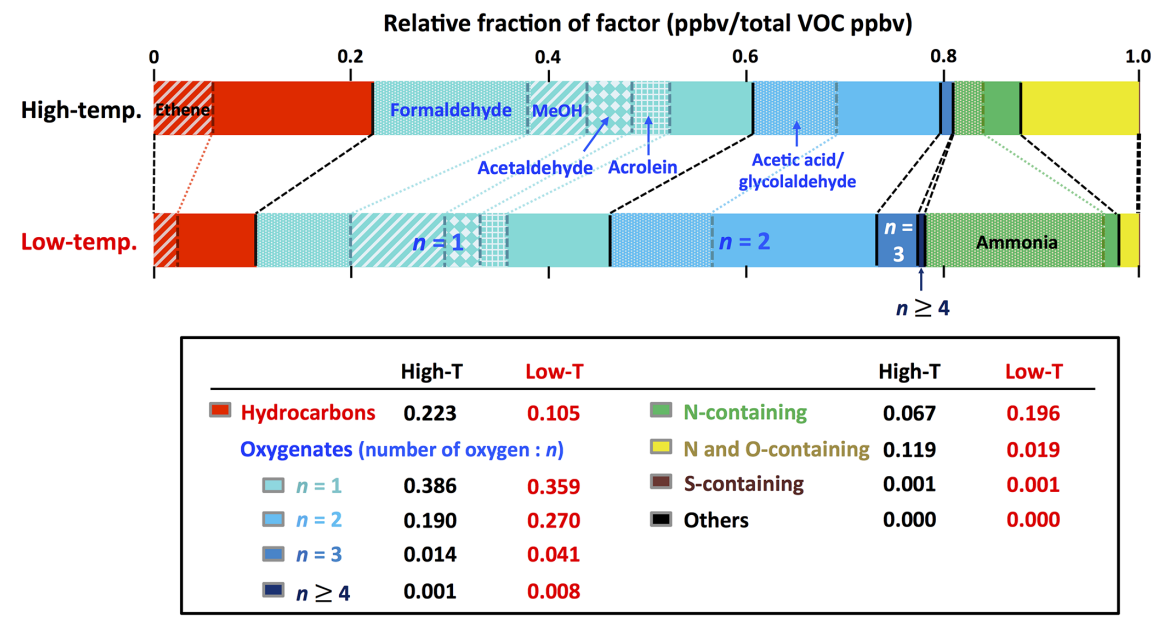

Figure 6. VOC composition in the high- and low-temperature emission profiles.

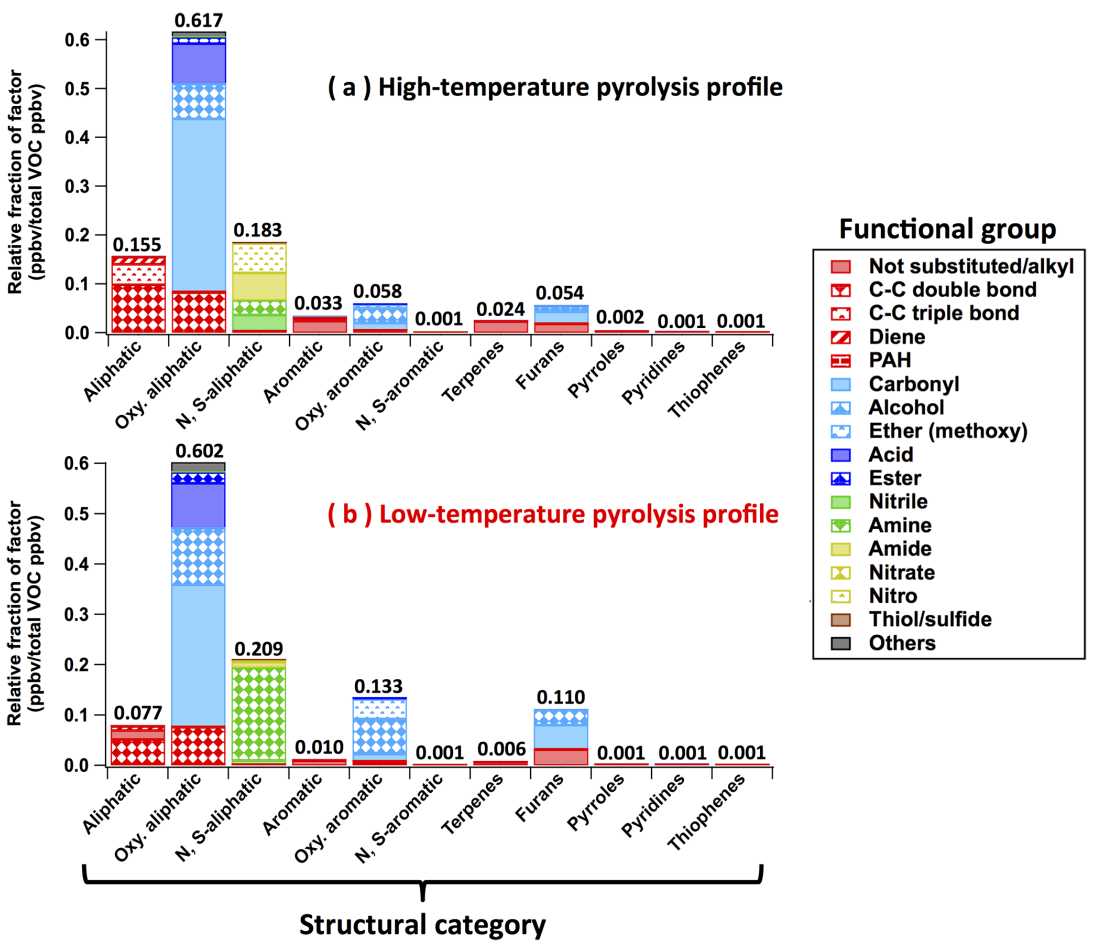

Figure 7. VOC composition in (a) high-temperature pyrolysis and (b) low-temperature pyrolysis emission profiles (Fig. 3) sorted by 11 structural categories and 17 functional groups. Some VOCs have multiple structures. These are counted once in each relevant category. For example, benzofuran is counted in the structural categories of "Oxy. aromatic" and "Furans" as "Not substituted/alkyl" functional group. Structures detected with low abundance $(<0.002$ ppbv per total VOC ppbv) are mostly not-substituted or alkyl-substituted.

been shown to be important biomass burning SOA precursors (Bruns et al., 2016), and while the SOA yields of many other compounds are unknown, the lower volatility and higher oxygen content of the low-temperature profile suggests a potentially more efficient SOA formation. SOA formation was also studied during the FIREX 2016 campaign, by oxidizing emissions in a chamber, and will be presented separately (Lim et al., 2018). We note that the compounds with $\mathrm{C}_{0}$
$<10^{2} \mu \mathrm{g} \mathrm{m}^{-3}$ shown in Fig. $9 \mathrm{~b}$ should be primarily in the particle phase and not measurable by PTR-MS without long delay times (Pagonis et al., 2017). However, the volatility of these compounds (calculated from the elemental composition) has an uncertainty of several orders of magnitude. Also, the cyclic compounds that are abundant in the lowtemperature profile, such as aromatic oxygenates, produce multifunctional ring-opening-products that are known to be 


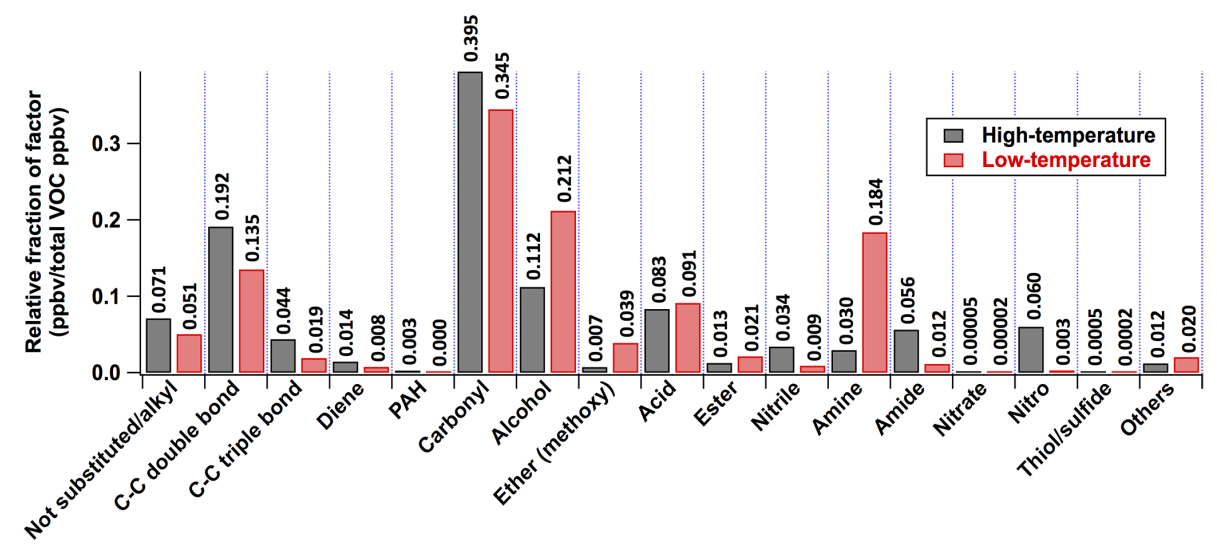

Figure 8. VOC composition in high- and low-temperature pyrolysis emission profiles (Fig. 3) sorted by 17 functional groups. Each group includes various structures and elemental composition. Some VOCs have multiple functional groups. These are counted once in each relevant category. For example, guaiacol is counted in the categories of "Alcohol" and "Ether (methoxy)".

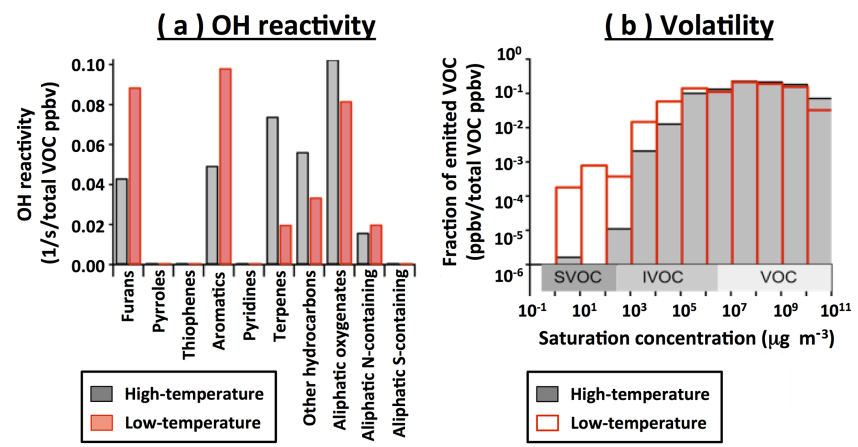

Figure 9. High- and low-temperature emission profiles compared by (a) $\mathrm{OH}$ reactivity and (b) volatility, described by saturation concentration $\left(\mu \mathrm{g} \mathrm{m}^{-3}\right)$.

efficient SOA precursors (Yee et al., 2013). In a similar manner to the $\mathrm{OH}$ reactivity, the total volatility distribution can be estimated from the relative importance of the high- and low-temperature pyrolysis in a given fire.

\subsection{Relationship of fuel characteristics to relative importance of high- and low-temperature pyrolysis factors}

To use the PMF profiles (Fig. 3) for estimates of VOC emissions from other fires, it is necessary to know the relative fire-integrated contributions of high- and low-temperature pyrolysis for those fires. As a step in this direction, in the present work, we found that fire-integrated molar emission ratios of total VOCs from high-temperature pyrolysis to lowtemperature pyrolysis, $\sum \mathrm{VOC}_{\text {high- } T}$ (in ppbv) $/ \sum \mathrm{VOC}_{\text {low- }}$ (in ppbv), are related to which parts of the plants are burned (blue bars in Fig. 10). When leafy fuels (i.e., canopy, shrub, and herbaceous fuels) are burned, the fraction of total VOC emissions originating from high-temperature pyrolysis is higher than those from low-temperature pyroly-

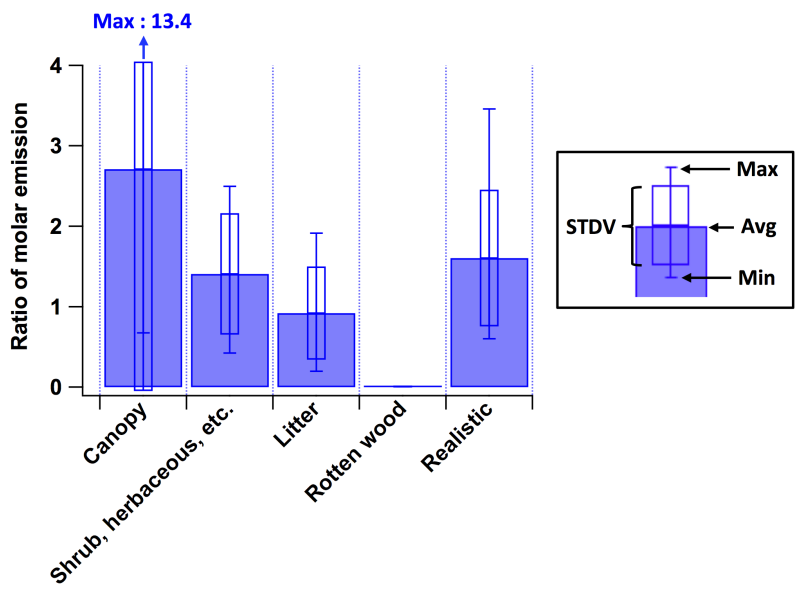

Figure 10. Ratios of fire-integrated molar emissions of total VOCs from high- to low-temperature pyrolysis (" $\sum \mathrm{VOC}_{\mathrm{High}-T} / \sum \mathrm{VOC}_{\mathrm{Low}-T}$ ") for different type fuel parts, obtained using PMF results of 15 different fuels.

sis. These results imply that surface-to-volume ratios and the content of biopolymers in a given fuel can strongly affect the relative importance of high- and low-temperature pyrolysis. Leaves have high surface-to-volume ratios and despite higher fuel moisture, at least the surface may tend to heat up easily, resulting in a higher contribution from the hightemperature factor. The higher monoterpene content of foliage may explain why low-temperature distillation products like monoterpenes are associated with the high-temperature pyrolysis factor.

In contrast, the burn of rotten wood was found to contain VOC emissions from low-temperature pyrolysis only. Our brown rotten wood samples were enriched in lignin (Kirk and Cowling, 1984). Lignin is relatively resistant to thermal decomposition compared to cellulose and hemicellulose. The temperature range where pyrolytic decomposition occurs sig- 
nificantly is $280-500^{\circ} \mathrm{C}$ for lignin, $240-350^{\circ} \mathrm{C}$ for cellulose, and $200-260^{\circ} \mathrm{C}$ for hemicellulose (Liu et al., 2016; Babu, 2008), as shown in Fig. 4b. In our laboratory fires, the rotten wood first smoldered for an extended period, and then flames were observed. However, only the low-temperature profile was observed. This suggests that it is more difficult for lignin-rich fuels to reach temperatures high enough to emit the "high-temperature pyrolysis" VOCs. Therefore, we do not see the same gradient in pyrolysis products that is observed for other fuel burns mainly consisting of cellulose and hemicellulose. Nitrogen content and speciation also vary between different biomass components, and temperature and differences in biopolymer content have been shown to strongly affect the composition of nitrogen-containing emissions (Hansson et al., 2004; Ren et al., 2011; Coggon et al., 2016). This is consistent with the observed differences in nitrogen speciation between the two profiles.

\subsection{High- and low-temperature pyrolysis profiles describe total VOC emissions}

Previous studies have found a correlation between the emission factors of certain VOCs and the fire-integrated modified combustion efficiency (MCE) (Yokelson et al., 1996, 1997; Selimovic et al., 2018). Thus, one might expect that the high- and low-temperature pyrolysis factors would also show a strong relationship to MCE. However, MCE does not parameterize the relative amounts of high- and low-temperature pyrolysis products very well, either instantaneously or on a fire-integrated basis (Fig. 11). The basic reason is that $\mathrm{CO}_{2}$ as well as $\mathrm{NO}_{x}$ are emitted overwhelmingly from flaming combustion, which is not the main source of most VOC emissions, and these emissions are not expected to correlate with a linear combination of the high- and low-temperature pyrolysis processes, while $\mathrm{CO}$ emissions are reasonably well correlated with an average of high- and low-temperature emissions (Figs. 1 and S6). This is especially clear in rotten log burns, where $\mathrm{CO}_{2}$ and the PMF profiles are not correlated. The $\mathrm{CO}_{2}$ emissions are enhanced by shifting from the smoldering to flaming combustion, but VOC emission patterns are not changed from the low- to high-temperature pyrolysis (Fig. S7). Consequently, $\mathrm{CO}_{2}$ and MCE, which indicate the separation between flaming and smoldering combustions, are not appropriate to estimate the high- and lowtemperature pyrolysis VOC emissions. Our results indicate that VOC emissions are even more closely correlated to the biopolymer composition and the surface-to-volume ratios of fuels, than to the MCE. It is also seen that for some fires the air temperature correlates with the high-temperature contribution (e.g., Fires no. 37 and no. 59 shown in Fig. S8a-c). This suggests that the VOC emissions are certainly related to the temperature within a fire. However, some other burns did not have a good correlation between the temperature and VOC emissions (e.g., Fire no. 38 shown in Fig. S8d), because the temperature measurement had some issues in the present work: (i) background temperature for each burn was different, (ii) some burns have colder temperature at the end compared to the start, which means that the laboratory was not controlled at constant temperature, and (iii) the increase in air temperature often lagged behind the emissions, especially at the start of a fire.

The relative contributions from the high- and lowtemperature processes could be estimated from ratios of distinct marker species that are consistently enhanced in the high- and low-temperature profiles. Several such pairs were considered and the ratio of ethyne $\left(\mathrm{C}_{2} \mathrm{H}_{2}\right)$ to furan $\left(\mathrm{C}_{4} \mathrm{H}_{4} \mathrm{O}\right)$ can reasonably predict the ratio of high- to low-temperature emissions as given in Eq. (1):

$$
\frac{\text { total VOC, high temperature (ppbv) }}{\text { total VOC, low temperature (ppbv) }}=\frac{\text { ethyne }(\mathrm{ppbv}) / 0.0393}{\text { furan }(\mathrm{ppbv}) / 0.0159} \text {. }
$$

The derivation and how the ethyne / furan ratio correlates with the high-temperature / low-temperature emission ratio are given in the Supplement (Sect. S2 and Fig. S9). However, this pair is not ideal because measurements of these two species are not frequently available and furan has high reactivity to both $\mathrm{O}_{3}$ and $\mathrm{NO}_{3}$ radicals. Future work should assess non-PTR measurements in order to find appropriate external markers.

Studies of laboratory burns and wildfires have reported variable emission ratios (or factors) for various VOCs as well as fire-integrated MCE, even for similar fuel types. Here we investigate how well total VOC emissions in biomass burning can be fit by the average VOC emission profiles (Fig. 3) using emission factors and ratios reported in the literature for laboratory and field burns (Gilman et al., 2015; Stockwell et al., 2015; Akagi et al., 2011). When fitting the present high- and low-temperature factors to the other biomass burning data, total VOC emissions can be described with different relative fractions of the factors (Fig. S10). For example, the best fit to a laboratory study by Gilman et al. (2015), using fuels from the southwestern, southeastern, and northern US (e.g., pine, spruce, fir, chaparral, mesquite, and oak) with $\mathrm{MCE}=0.75-0.98$, includes $32 \%$ high-temperature and $68 \%$ low-temperature VOC emissions; for another laboratory study by Stockwell et al. (2015) including several types of grass, spruce, and chaparral with $\mathrm{MCE}=0.68-0.99$, high temperatures of $59 \%$ and low temperatures of $41 \%$ were found; temperate forest fires $(\mathrm{MCE}=0.95)$ reported by Akagi et al. (2011) showed $77 \%$ high temperature and $23 \%$ low temperature, while in the case of chaparral fires $(\mathrm{MCE}=0.96)$, high temperatures of $48 \%$ and low temperatures of $52 \%$ were found. The fitting can be done with high correlation coefficient $(r \geq 0.92)$ for all the literature data (Fig. S10). This is further evidence that at most two factors can explain the majority of VOC variability. Therefore, these two factors could be used to fill in VOCs not measured in the other studies which sometimes had less chemical detail. The current study incorporated a wide range of MCEs and fuel moisture contents (Table 1), so the two-factor description 

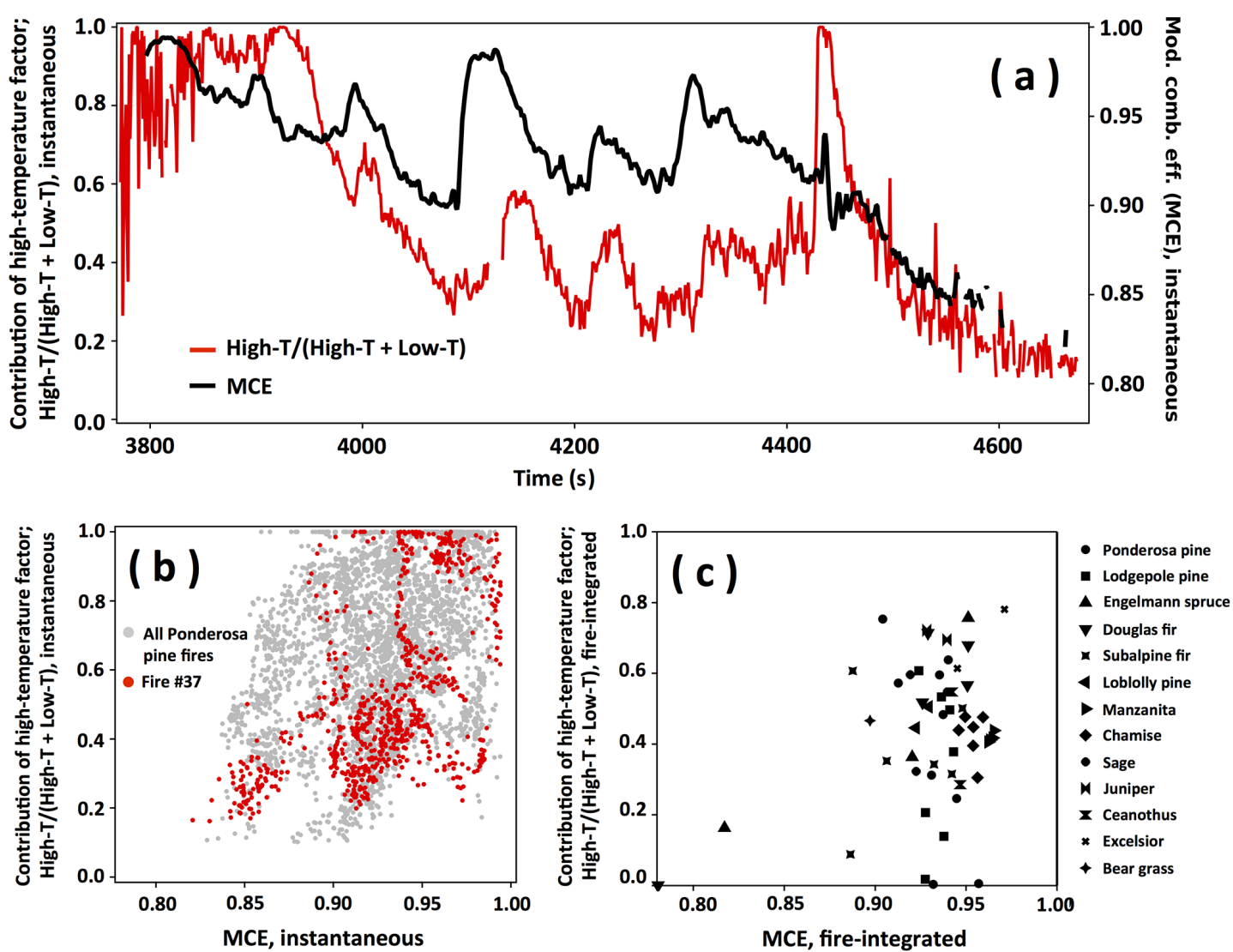

Figure 11. The comparison of contribution of high-temperature factor versus modified combustion efficiency (MCE). (a) Time series of Fire no. 37 (ponderosa pine realistic mixture). (b) Scatter plot of instantaneous high-temperature contribution versus MCE for all ponderosa pine fires. (c) Scatter plot of fire-integrated high-temperature contribution versus MCE for all fires. Contribution of high-temperature factor was calculated by $\Sigma \mathrm{VOC}_{\mathrm{high}-T} /\left(\Sigma \mathrm{VOC}_{\mathrm{high}-T}+\Sigma \mathrm{VOC}_{\text {low- } T}\right)$ instantaneously or on a fire-integrated basis. $\mathrm{T}=$ temperature.

may be applicable under many conditions. However, some other factors should be required for specific burns, as discussed below.

\subsection{Emission of specific compounds}

\subsubsection{Distillation phase}

At the beginning of many burn experiments, white smoke is visible immediately prior to ignition. This "distillation phase" does not result from pyrolysis or combustion, but rather a gradual heating and release of water and volatile compounds trapped within the biomass. This phase of the fire was not distinguished by PMF. The distillation phase from coniferous fuels is enriched in some compounds highly relevant to atmospheric chemistry, especially terpenes (Koss et al., 2018). But this phase lasts only a short time (typically less than $10 \mathrm{~s}$ ), in which only a short spike in emissions is observed. Accordingly, PMF cannot capture this phase effectively even if a large number of factors is chosen. As an exception, the distillation phase of sagebrush, enriched in terpenes and a specific oxygenated monoterpene (camphor), can be distinguished as a third PMF factor, because that phase lasted longer than $30 \mathrm{~s}$ in that fire. The reported overall residual of $15 \%$ includes the poorly fitted distillation phase, and we stress that it typically accounts for only a small portion of the overall emissions. Additionally, with the exception of terpenes, the composition of the distillation profile is similar to that of the high-temperature profile.

For some fuel burns other than coniferous fuels (e.g., manzanita), VOC emissions during the distillation phase are quite small, although distillation smoke is visible. In these cases, PMF incorporates this phase into the low-temperature pyrolysis factor. There may be a relationship between the VOC emission process coincident with distillation (low- or hightemperature) and the presence of visible smoke. For instance, perhaps here the temperatures are low enough that the compounds are able to recondense into visible smoke.

\subsubsection{Duff burn}

A fourth factor can be resolved from the PMF analysis of duff burns. The distribution of VOC structures and functionality in the duff emission profiles (Fig. 12a) is similar 


\section{(a) VOC emission profile of duff burn}

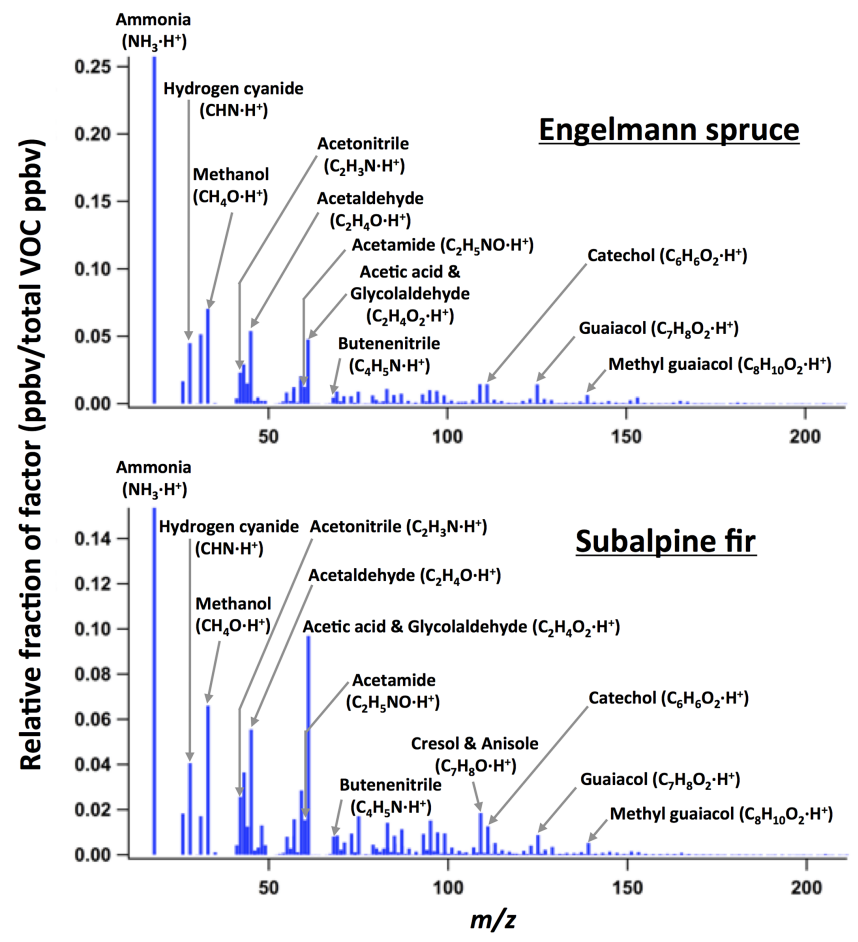

\section{(b) Duff profile vs. low-temp. profile}

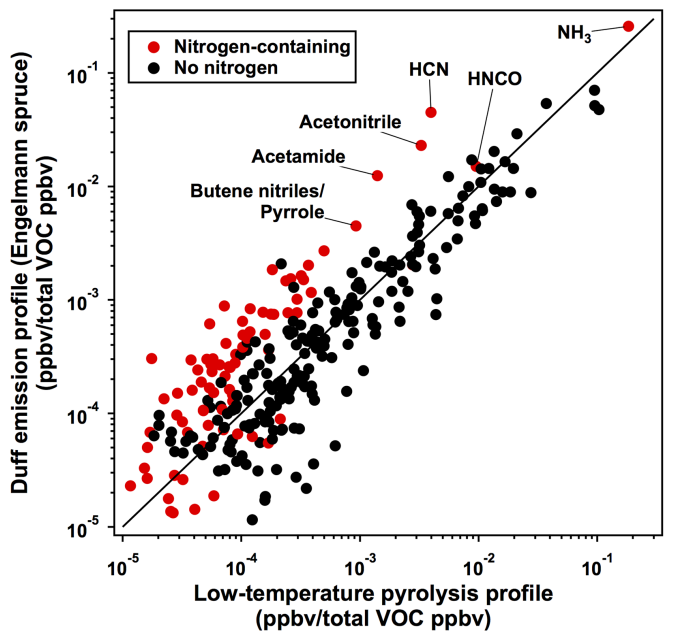

Figure 12. (a) VOC emission profile of duff burn of Engelmann spruce and subalpine fir. (b) Scatter plot of duff emission profile (Engelmann spruce) versus average low-temperature pyrolysis profile.

to the low-temperature pyrolysis profile (Fig. 12b). The major difference is much higher emission of aliphatic nitrogencontaining compounds: $56 \%$ more of these compounds are emitted per ppbv of VOCs in the duff profile than in the lowtemperature profile. The additional emissions are mostly nitriles and amides, especially hydrogen cyanide, acetonitrile, and acetamide. Pyrroles and pyridines are also enhanced, but are much less abundant overall.

The organic portion of duff is enriched in nitrogen relative to other components of coniferous fuels. The nitrogen-tocarbon ratio in the subalpine fir duff $(\mathrm{N}: \mathrm{C}$ ratio $=0.028$ by weight) was a factor of 2.1 higher than the average of other subalpine fir components, and the Engelmann spruce duff $\mathrm{N}: \mathrm{C}$ ratio $(0.022)$ was $1.3 \times$ higher than other Engelmann spruce components. Coggon et al. (2016), who investigated VOC emissions from the burning of herbaceous and arboraceous fuels, also found that the nitrogen-containing fraction of VOCs emitted from biomass burning increased with the nitrogen content of the fuel.

However, the nitrogen content cannot entirely explain why duff has a unique emission profile. Other fuels, such as ceanothus and ponderosa pine litter, have similar $\mathrm{N}: \mathrm{C}$ ratios ( 0.025 and 0.022 , respectively ) but are explained well by the two-factor PMF solution consisting of high- and lowtemperature pyrolysis factors. The contradiction may be due to differences in the speciation of nitrogen-containing organics. In woody and leafy fuels, proteins and amino acids account for $80-85 \%$ of the organic nitrogen (Ren and Zhao, 2015). In soils, proteins account for typically only $40 \%$ of organic nitrogen, and heterocyclic nitrogen compounds (pyrroles and pyridines) account for 35\% (Schulten and Schnitzer, 1997). Pyrolysis of nitrogen heterocycles releases $\mathrm{HCN}$, while proteins and amino acids may release more $\mathrm{NH}_{3}$ (Leppälahti and Koljonen, 1995). This is consistent with the higher HCN and nitriles characteristic of the duff emission profile.

\subsubsection{Variation in specific VOCs between fuels}

When comparing emission profiles of individual fuels to the average profiles shown in Fig. 3, there are some specific compounds whose emissions are notably higher $(>\times 5)$ or lower $(<\times 0.2)$ than the average (Fig. S4). Here we highlight several key features:

i. For ponderosa, lodgepole, and loblolly pines; Douglas and subalpine firs; and juniper, the emission of benzoquinone $\left(\mathrm{C}_{6} \mathrm{H}_{4} \mathrm{O}_{2} \cdot \mathrm{H}^{+}, \mathrm{m} / \mathrm{z}\right.$ 109.028) is quite low in the high-temperature pyrolysis: $7-21 \%$ of the average emission for the pines and firs, and $2 \%$ for juniper (Fig. S4a-1-4, 6, and 7).

ii. For fuels other than coniferous fuels and sagebrush, i.e., bear grass, excelsior, ceanothus, chamise, and manzanita, emissions of monoterpenes $\left(\mathrm{C}_{10} \mathrm{H}_{16} \cdot \mathrm{H}^{+}\right.$, $m / z 137.132$ ) are only $2-15 \%$ of the average (Fig. S4a$8-14)$.

iii. Excelsior emits especially low quantities of nitrogencontaining compounds, especially nitriles (hydrogen cyanide, acetonitrile, acrylonitrile, and propane nitrile) and pyridine, in the high-temperature pyrolysis 
(Fig. S4a-9). This is because the nitrogen content in excelsior is significantly lower than other fuels. The excelsior $\mathrm{N}$ : $\mathrm{C}$ ratio ( 0.005 by weight $)$ is $3.6 \times$ lower than the average of other fuels $(0.017 \pm 0.006)$.

iv. High-temperature pyrolysis of ceanothus produces quite high emission of benzofuran-type compounds (Fig. S4a-10). Benzofuran $\left(\mathrm{C}_{8} \mathrm{H}_{6} \mathrm{O} \cdot \mathrm{H}^{+}, m / z\right.$ 119.049) and methylbenzofuran and possibly a methylbenzofuran isomer such as cinnamaldehyde $\left(\mathrm{C}_{9} \mathrm{H}_{8} \mathrm{O} \cdot \mathrm{H}^{+}\right.$, $\mathrm{m} / \mathrm{z} 133.065)$ are 5.5 and $10.1 \times$ higher than the average, respectively.

v. Sagebrush specifically emits camphor $\left(\mathrm{C}_{10} \mathrm{H}_{16} \mathrm{O} \cdot \mathrm{H}^{+}\right.$, $\mathrm{m} / z$ 153.127) in high-temperature pyrolysis (Fig. S4a$15)$.

vi. There are a limited number of exceptions in lowtemperature profiles (Fig. S4b). This means that lowtemperature pyrolysis gives almost identical VOC emissions, independent of fuel types.

\section{Conclusions}

This work focused on interpretation of VOC emissions from biomass burning. We provided an understanding of VOC variability based on known chemical and physical processes to release VOCs from fires. We explained most of the observed variability between VOC emissions from fuel types and over the course of a fire using just two emission profiles: (i) a high-temperature pyrolysis profile and (ii) a lowtemperature pyrolysis profile. The results are summarized as follows:

1. The two profiles can explain the variability in VOC emissions composition between different fuel types and over the course of individual fires, with an average residual of $<15 \%$.

2. The high-temperature profile is quantitatively similar between different fuel types $\left(r^{2}>0.84\right)$, and likewise for the low-temperature profile.

3. The two profiles are significantly different in terms of VOC composition, volatility, and contributors to $\mathrm{OH}$ reactivity. The high-temperature pyrolysis profile is enriched in aliphatic unsaturated hydrocarbons, (polycyclic) aromatic hydrocarbons, terpenes (emitted from distillation), $\mathrm{HCN}, \mathrm{HNCO}$, and HONO. The resulting $\mathrm{OH}$ reactivity is primarily attributed to terpenes, aliphatic hydrocarbons, and nonaromatic oxygenates. The low-temperature pyrolysis profile is enriched in aromatic oxygenates, furans, and $\mathrm{NH}_{3}$. Furans and aromatics contribute significantly to the $\mathrm{OH}$ reactivity.

4. The fire-integrated molar emission ratios of total VOCs from high-temperature pyrolysis to low-temperature pyrolysis are related to the biopolymer composition and surface-to-volume ratios of fuels. Higher surface-tovolume ratios lead to more total VOC emissions enriched in products resulting from high-temperature pyrolysis than from those resulting from low-temperature pyrolysis.

5. The two VOC profiles can model previously reported VOC data for laboratory and field burns $(r \geq 0.92)$. This suggests that these two profiles could be used to fill in VOCs not actually measured in the previous studies which sometimes had less chemical detail.

6. MCE, which parameterizes flaming and smoldering combustion, is not appropriate to estimate the high- and low-temperature pyrolysis VOC emissions. This suggests that the high- and low-temperature pyrolysis profiles may provide information on emissions that is not accessible with a broader definition of smoldering combustion implicit in the use of MCE.

7. Duff burns emit a specific VOC profile which is similar to that of low-temperature pyrolysis, but additionally includes aliphatic nitrogen-containing compounds, especially $\mathrm{HCN}$, acetonitrile, and acetamide.

Our framework provides a way to understand VOC emissions variability in other laboratory and field studies of biomass burning. We highlight two areas of useful future work. First, external tracers should be found that will allow the prediction of the relative contribution of individual profiles. This could include specific chemical species, an understanding of how fuel or burn characteristics relate to the relative contribution of the two profiles, or a relationship between some measure of fire temperature and the VOC profiles. Second, the SOA and ozone formation potential of the two profiles should be determined. With this further work, the VOC profiles could be widely useful to model VOC emissions from many types of biomass burning in the western US, with additions to the framework being needed for fires that burn a lot of duff.

Future work should also include a quantitative comparison of the VOC PMF results to measurements of aerosol, inorganic gases, and organic species not measured by PTRToF-MS. Such a comparison would help define the relationship between VOCs and characteristics of primary organic aerosol. We note that the primary aerosols have also been shown to have distinct profiles that correlate with different pyrolysis and combustion processes in the fire (Reece et al., 2017; Haslett et al., 2018).

Data availability. Data are available from the CSD NOAA archive at https://esrl.noaa.gov/csd/groups/csd7/measurements/2016firex/ FireLab/DataDownload/. The credentials of this archive can be obtained by contacting the corresponding author. 
Supplement. The supplement related to this article is available online at: https://doi.org/10.5194/acp-18-9263-2018-supplement.

Author contributions. KS, ARK, CW, RJY, JMR, and JdG designed the research. KS, ARK, JBG, VS, MMC, KJZ, BY, BML, SSB, $\mathrm{CW}, \mathrm{RJY}$, and JdG performed the measurements and/or contributed to the data analysis. All authors contributed to the discussion and interpretation of the results and writing the paper.

Competing interests. The authors declare that they have no conflict of interest.

Acknowledgements. Kanako Sekimoto acknowledges the Postdoctoral Fellowships for Research Abroad from the Japan Society for the Promotion of Science (JSPS) and a Grant-in-Aid for Young Scientists (B) (15K16117) from the Ministry of Education, Culture, Sports, Science and Technology of Japan. Abigail R. Koss acknowledges support from the NSF Graduate Fellowship Program. Matthew M. Coggon acknowledges the Visiting Postdoctoral Fellowship from the Cooperative Institute for Research in Environmental Sciences (CIRES). Vanessa Selimovic and Robert J. Yokelson were supported by NOAA-CPO grant NA16OAR4310100. Joost de Gouw worked as a consultant for Aerodyne Research Inc. during part of the preparation phase of this paper. We thank for support from NOAA AC4 external funding, and thank the USFS Missoula Fire Sciences Laboratory for their assistance and cooperation. This work was also supported in part by NOAA's Climate Change and Health of the Atmosphere initiatives.

Edited by: Jacqui Hamilton

Reviewed by: two anonymous referees

\section{References}

Akagi, S. K., Yokelson, R. J., Wiedinmyer, C., Alvarado, M. J., Reid, J. S., Karl, T., Crounse, J. D., and Wennberg, P. O.: Emission factors for open and domestic biomass burning for use in atmospheric models, Atmos. Chem. Phys., 11, 4039-4072, https://doi.org/10.5194/acp-11-4039-2011, 2011.

Alvarado, M. J., Wang, C, and Prinn, R. G.: Formation of ozone and growth of aerosols in young smoke plumes from biomass burning: 2. Three-dimensional Eulerian studies, J. Geophys. Res., 114, D09307, https://doi.org/10.1029/2008JD011186, 2009.

Alvarado, M. J., Lonsdale, C. R., Yokelson, R. J., Akagi, S. K., Coe, H., Craven, J. S., Fischer, E. V., McMeeking, G. R., Seinfeld, J. H., Soni, T., Taylor, J. W., Weise, D. R., and Wold, C. E.: Investigating the links between ozone and organic aerosol chemistry in a biomass burning plume from a prescribed fire in California chaparral, Atmos. Chem. Phys., 15, 6667-6688, https://doi.org/10.5194/acp-15-6667-2015, 2015.

Atkinson, R. and Arey, J.: Atmospheric degradation of volatile organic compounds, Chem. Rev., 103, 4605-4638, https://doi.org/10.1021/cr0206420, 2003.
Babu, B. V.: Biomass pyrolysis: a state-of-the-art review, Biofuel. Bioprod. Bior., 2, 393-414, https://doi.org/10.1002/bbb.92, 2008.

Bruns, E. A., El Haddad, I., Slowik, J. G., Kilic, D., Klein, F., Baltensperger, U., and Prévôt, A. S. H.: Identification of significant precursor gases of secondary organic aerosols from residential wood combustion, Sci. Rep., 6, 27881, https://doi.org/10.1038/srep27881, 2016.

Burling, I. R., Yokelson, R. J., Griffith, D. W. T., Johnson, T. J., Veres, P., Roberts, J. M., Warneke, C., Urbanski, S. P., Reardon, J., Weise, D. R., Hao, W. M., and de Gouw, J.: Laboratory measurements of trace gas emissions from biomass burning of fuel types from the southeastern and southwestern United States, Atmos. Chem. Phys., 10, 11115-11130, https://doi.org/10.5194/acp-10-11115-2010, 2010.

Christian, T. J., Kleiss, B., Yokelson, R. J., Holzinger, R., Crutzen, P. J., Hao, W. M., Saharjo, B. H., and Ward, D. E.: Comprehensive laboratory measurements of biomass-burning emissions: 1. Emissions from Indonesian, African and other fuels, J. Geophys. Res., 108, 4719, https://doi.org/10.1029/2003JD003704, 2003.

Christian, T. J., Kleiss, B., Yokelson, R. J., Holzinger, R., Crutzen, P. J., Hao, W. M., Shirai, T., and Blake, D. R.: Comprehensive laboratory measurements of biomassburning emissions: 2. First intercomparison of open-path FTIR, and GC-MS/FID/ECD, J. Geophys. Res., 109, D02311, https://doi.org/10.1029/2003JD003874, 2004.

Cicerone, R. J. and Zellner, R.: The atmospheric chemistry of hydrogen cyanide (HCN), J. Geophys. Res., 88, 10689-10696, https://doi.org/10.1029/JC088iC15p10689, 1983.

Coggon, M. M., Veres, P. R., Yuan, B., Koss, A., Warneke, C., Gilman, J. B., Lerner, B. M., Peischl, J., Aikin, K. C., Stockwell, C. E., Hatch, L. E., Ryerson, T. B., Roberts, J. M., Yokelson, R. J., and de Gouw, J. A.: Emissions of nitrogen-containing organic compounds from the burning of herbaceous and arboraceous biomass: Fuel composition dependence and the variability of commonly used nitrile tracers, Geophys. Res. Lett., 43, 99039912, https://doi.org/10.1002/2016GL070562, 2016.

Collard, F. X. and Blin, J.: A review on pyrolysis of biomass constituents: Mechanisms and composition of the products obtained from the conversion of cellulose, hemicelluloses and lignin, Renew. Sust. Energ. Rev., 38, 594-608, https://doi.org/10.1016/j.rser.2014.06.013, 2014.

Donahue, N. M., Epstein, S. A., Pandis, S. N., and Robinson, A. L.: A two-dimensional volatility basis set: 1. organic-aerosol mixing thermodynamics, Atmos. Chem. Phys., 11, 3303-3318, https://doi.org/10.5194/acp-11-3303-2011, 2011.

Gilman, J. B., Lerner, B. M., Kuster, W. C., Goldan, P. D., Warneke, C., Veres, P. R., Roberts, J. M., de Gouw, J. A., Burling, I. R., and Yokelson, R. J.: Biomass burning emissions and potential air quality impacts of volatile organic compounds and other trace gases from $\mathrm{f}$ uels common in the US, Atmos. Chem. Phys., 15, 13915-13938, https://doi.org/10.5194/acp-15-139152015, 2015.

Haidar, N. F., Patterson, J. M., Moors, M., and Smith, W. T.: Effects of structure on pyrolysis gases from amino acids, J. Agr. Food. Chem., 29, 163-165, https://doi.org/10.1021/jf00103a040, 1981.

Hansson, K.-M., Samuelsson, J., Tullin, C., and Åmand, L.-E.: Formation of HNCO, HCN, and $\mathrm{NH} 3$ 
from the pyrolysis of bark and nitrogen-containing model compounds, Combust. Flame, 137, 265-277, https://doi.org/10.1016/J.COMBUSTFLAME.2004.01.005, 2004.

Haslett, S. L., Thomas, J. C., Morgan, W. T., Hadden, R., Liu, D., Allan, J. D., Williams, P. I., Keita, S., Liousse, C., and Coe, H.: Highly controlled, reproducible measurements of aerosol emissions from combustion of a common African biofuel source, Atmos. Chem. Phys., 18, 385-403, https://doi.org/10.5194/acp-18385-2018, 2018.

Hatch, L. E., Luo, W., Pankow, J. F., Yokelson, R. J., Stockwell, C. E., and Barsanti, K. C.: Identification and quantification of gaseous organic compounds emitted from biomass burning using two-dimensional gas chromatography-time-offlight mass spectrometry, Atmos. Chem. Phys., 15, 1865-1899, https://doi.org/10.5194/acp-15-1865-2015, 2015.

Hatch, L. E., Yokelson, R. J., Stockwell, C. E., Veres, P. R., Simpson, I. J., Blake, D. R., Orlando, J. J., and Barsanti, K. C.: Multi-instrument comparison and compilation of non-methane organic gas emissions from biomass burning and implications for smoke-derived secondary organic aerosol precursors, Atmos. Chem. Phys., 17, 1471-1489, https://doi.org/10.5194/acp17-1471-2017, 2017.

Houser, T. J., McCarville, M. E., and Biftu, T.: Kinetics of the thermal decomposition of pyridine in a flow system, Int. J. Chem. Kinet., 12, 555-568, https://doi.org/10.1002/kin.550120806, 1980.

Jaffe, D. A. and Wigder, N. L.: Ozone production from wildfires: A critical review, Atmos. Environ., 51, 1-10, https://doi.org/10.1016/j.atmosenv.2011.11.063, 2012.

Johnson, W. R. and Kan, J. C.: Mechanisms of hydrogen cyanide formation from the pyrolysis of amino acids and related compounds, J. Org. Chem., 36, 189-192, https://doi.org/10.1021/jo00800a038, 1971.

Kirk, T. K. and Cowling, E. B.: Biological decomposition of solid wood, Adv. Chem., 207, 455-487, https://doi.org/10.1021/ba1984-0207.ch012, 1984

Koss, A. R., Sekimoto, K., Gilman, J. B., Selimovic, V., Coggon, M. M., Zarzana, K. J., Yuan, B., Lerner, B. M., Brown, S. S., Jimenez, J. L., Krechmer, J., Roberts, J. M., Warneke, C., Yokelson, R. J., and de Gouw, J.: Non-methane organic gas emissions from biomass burning: identification, quantification, and emission factors from PTR-ToF during the FIREX 2016 laboratory experiment, Atmos. Chem. Phys., 18, 3299-3319, https://doi.org/10.5194/acp-18-3299-2018, 2018.

Leppälahti, J. and Koljonen, T.: Nitrogen evolution from coal, peat and wood during gasification: Literature review, Fuel Process. Technol., 43, 1-45, https://doi.org/10.1016/03783820(94)00123-B, 1995.

Li, Y., Pöschl, U., and Shiraiwa, M.: Molecular corridors and parameterizations of volatility in the chemical evolution of organic aerosols, Atmos. Chem. Phys., 16, 3327-3344, https://doi.org/10.5194/acp-16-3327-2016, 2016.

Lim, C., Hagan, D., Cappa, C., Coggon, M., Koss, A., Sekimoto, K., de Gouw, J., Warneke, C., and Kroll, J.: Laboratory studies on the aging of biomass burning emissions: chemical evolution and secondary organic aerosol yield, in preparation, 2018.
Liu, W. -J., Li, W. -W., Jiang, H., and Yu, H.-Q.: Fates of chemical elements in biomass during its pyrolysis, Chem. Rev., 117, 63676398, https://doi.org/10.1021/acs.chemrev.6b00647, 2016.

Manion, J. A., Huie, R. E., Levin, R. D., Burgess Jr., D. R., Orkin, V. L., Tsang, W., McGivern, W. S., Hudgens, J. W., Knyazev, V. D., Atkinson, D. B., Chai, E., Tereza, A. M., Lin, C.-Y., Allison, T. C., Mallard, W. G., Westley, F., Herron, J. T., Hampson, R. F., and Frizzell, D. H.: NIST Chemical Kinetics Database, NIST Standard Reference Database 17, Version 7.0 (Web Version), Release 1.6.8, Data version 2015.12, National Institute of Standards and Technology, Gaithersburg, Maryland, 20899-8320, available at: https://kinetics.nist.gov/kinetics/index.jsp, last access: 28 November 2017.

Naeher, L. P., Brauer, M., Lipsett, M., Zelikoff, J. T., Simpson, C. D., Koenig, J. Q., and Smith, K. R.: Woodsmoke health effects: A review, Inhal. Toxicol., 19, 67-106, https://doi.org/10.1080/08958370600985875, 2007.

NIST Chemistry WebBook: NIST Standard Reference Database Number 69, available at: http://webbook.nist.gov/chemistry/, last access: 28 November 2017.

Paatero, P.: Least squares formulation of robust non-negative factor analysis, Chemometr. Intell. Lab., 37, 23-35, https://doi.org/10.1016/S0169-7439(96)00044-5, 1997.

Paatero, P. and Tapper, U.: Positive matrix factorization: A non-negative factor model with optimal utilization of error estimates of data values, Environmetrics, 5, 111-126, https://doi.org/10.1002/env.3170050203, 1994.

Pagonis, D., Krechmer, J. E., de Gouw, J., Jimenez, J. L., and Ziemann, P. J.: Effects of gas-wall partitioning in Teflon tubing and instrumentation on time-resolved measurements of gasphase organic compounds, Atmos. Meas. Tech., 10, 4687-4696, https://doi.org/10.5194/amt-10-4687-2017, 2017.

Patterson, J. M., Tsamasfyros, A., and Smith, W. T.: Pyrolysis of pyrrole, J. Heterocyclic Chem., 5, 727-729, https://doi.org/10.1002/jhet.5570050527, 1968.

Reardon, J.: Duff, in: FireWords: Fire Science Glossary [electronic], U.S. Department of Agriculture, Forest Service, Rocky Mountina Research Station, Fire Science Laboratory (Producer), available at: http://www.firewords.net (last access: 28 November 2017), 2007.

Reece, S. M., Sinha, A., and Grieshop, A. P.: Primary and photochemically aged aerosol emissions from biomass cookstoves: Chemical and physical characterization, Environ. Sci. Technol., 51, 9379-9390, https://doi.org/10.1021/acs.est.7b01881, 2017.

Ren, Q. and Zhao, C.: Evolution of fuel-N in gas phase during biomass pyrolysis, Renew. Sust. Energ. Rev., 50, 408-418, https://doi.org/10.1016/j.rser.2015.05.043, 2015.

Ren, Q., Zhao, C., Chen, X., Duan, L., Li, Y., and Ma, C.: $\mathrm{NO}_{x}$ and $\mathrm{N}_{2} \mathrm{O}$ precursors $\left(\mathrm{NH}_{3}\right.$ and $\left.\mathrm{HCN}\right)$ from biomass pyrolysis: Co-pyrolysis of amino acids and cellulose, hemicellulose and lignin, P. Combust. Inst., 33, 1715-1722, https://doi.org/10.1016/J.PROCI.2010.06.033, 2011.

Roberts, J. M, Veres, P. R., Cochran, A. K., Warneke, C., Burling, I. R., Yokelson, R. J., Lerner, B., Gilman, J. B., Kuster, W. C., Fall, R., and de Gouw, J.: Isocyanic acid in the atmosphere and its possible link to smoke-related health effects, P. Natl. Acad. Sci. USA, 208, 8966-8971, https://doi.org/10.1073/pnas.1103352108, 2011. 
Rumble, J. R.: CRC Handbook of Chemistry and Physics, 98th Edn., CRC Press, Boca Raton, Florida, USA, 2017-2018.

Schulten, H.-R. and Schnitzer, M.: The chemistry of soil organic nitrogen: a review, Biol. Fert. Soils., 26, 1-15, 1997.

Selimovic, V., Yokelson, R. J., Warneke, C., Roberts, J. M., de Gouw, J., Reardon, J., and Griffith, D. W. T.: Aerosol optical properties and trace gas emissions by PAX and OP-FTIR for laboratory-simulated western US wildfires during FIREX, Atmos. Chem. Phys., 18, 2929-2948, https://doi.org/10.5194/acp18-2929-2018, 2018.

Stockwell, C. E., Veres, P. R., Williams, J., and Yokelson, R. J.: Characterization of biomass burning emissions from cooking fires, peat, crop residue, and other fuels with high-resolution proton-transfer-reaction time-of-flight mass spectrometry, Atmos. Chem. Phys., 15, 845-865, https://doi.org/10.5194/acp-15845-2015, 2015.

Ulbrich, I. M., Canagaratna, M. R., Zhang, Q., Worsnop, D. R., and Jimenez, J. L.: Interpretation of organic components from Positive Matrix Factorization of aerosol mass spectrometric data, Atmos. Chem. Phys., 9, 2891-2918, https://doi.org/10.5194/acp-92891-2009, 2009.

Yaws, C. L.: The Yaws Handbook of Vapor Pressure: Antoine Coefficients, Elsevier Science, Amsterdam, the Netherlands, 2015.

Yee, L. D., Kautzman, K. E., Loza, C. L., Schilling, K. A., Coggon, M. M., Chhabra, P. S., Chan, M. N., Chan, A. W. H., Hersey, S. P., Crounse, J. D., Wennberg, P. O., Flagan, R. C., and Seinfeld, J. H.: Secondary organic aerosol formation from biomass burning intermediates: phenol and methoxyphenols, Atmos. Chem. Phys., 13, 8019-8043, https://doi.org/10.5194/acp13-8019-2013, 2013.
Yokelson, R. J., Griffith, D. W. T., and Ward, D. E.: Openpath Fourier transform infrared studies of large-scale laboratory biomass fires, J. Geophys. Res.-Atmos., 101, 21067-21080, https://doi.org/10.1029/96JD01800, 1996.

Yokelson, R. J., Susott, R., Ward, D. E., Reardon, J., and Griffith, D. W. T.: Emissions from smoldering combustion of biomass measured by open-path Fourier transform infrared spectroscopy, J. Geophys. Res.-Atmos., 102, 18865-18877, https://doi.org/10.1029/97JD00852, 1997.

Yokelson, R. J., Crounse, J. D., DeCarlo, P. F., Karl, T., Urbanski, S., Atlas, E., Campos, T., Shinozuka, Y., Kapustin, V., Clarke, A. D., Weinheimer, A., Knapp, D. J., Montzka, D. D., Holloway, J., Weibring, P., Flocke, F., Zheng, W., Toohey, D., Wennberg, P. O., Wiedinmyer, C., Mauldin, L., Fried, A., Richter, D., Walega, J., Jimenez, J. L., Adachi, K., Buseck, P. R., Hall, S. R., and Shetter, R.: Emissions from biomass burning in the Yucatan, Atmos. Chem. Phys., 9, 5785-5812, https://doi.org/10.5194/acp-9-57852009, 2009.

Yuan, B., Koss, A., Warneke, C., Gilman, J. B., Lerner, B. M., Stark, H., and de Gouw, J. A.: A high-resolution time-of-flight chemical ionization mass spectrometer utilizing hydronium ions $\left(\mathrm{H}_{3} \mathrm{O}^{+}\right.$ToF-CIMS) for measurements of volatile organic compounds in the atmosphere, Atmos. Meas. Tech., 9, 2735-2752, https://doi.org/10.5194/amt-9-2735-2016, 2016.

Yuan, B., Koss, A., Warneke, C., Coggon, M., Sekimoto, K., and de Gouw, J. A.: Proton-transfer-reaction mass spectrometry: Applications in atmospheric sciences, Chem. Rev., 117, 13187-13229, https://doi.org/10.1021/acs.chemrev.7b00325, 2017. 